\title{
Determining the Shear Capacity of Steel Beams with Corrugated Webs by Using Optimised Regression Learner Techniques
}

\author{
Ahmed S. Elamary ${ }^{1, *}$ and Ibrahim B. M. Taha ${ }^{2}$ \\ 1 Civil Engineering Department, College of Engineering, Taif University, P.O. Box 11099, \\ Taif 21944, Saudi Arabia \\ 2 Electrical Engineering Department, College of Engineering, Taif University, P.O. Box 11099, \\ Taif 21944, Saudi Arabia; i.taha@tu.edu.sa \\ * Correspondence: a.elamary@tu.edu.sa; Tel.: +966-581338825
}

Citation: Elamary, A.S.; Taha, I.B.M. Determining the Shear Capacity of Steel Beams with Corrugated Webs by Using Optimised Regression Learner Techniques. Materials 2021, 14, 2364. https://doi.org/10.3390/ma14092364

Academic Editor: Michele Bacciocchi

Received: 9 April 2021

Accepted: 29 April 2021

Published: 1 May 2021

Publisher's Note: MDPI stays neutral with regard to jurisdictional claims in published maps and institutional affiliations.

Copyright: (c) 2021 by the authors. Licensee MDPI, Basel, Switzerland. This article is an open access article distributed under the terms and conditions of the Creative Commons Attribution (CC BY) license (https:// creativecommons.org/licenses/by/ $4.0 /)$.

\begin{abstract}
The use of corrugated webs increases web shear stability and eliminates the need for transverse stiffeners in steel beams. Optimised regression learner techniques (ORLTs) are rarely used for calculating shear capacity in steel beam research. This study proposes a new approach for calculating the maximum shear capacity of steel beams with trapezoidal corrugated webs (SBCWs) by using ORLTs. A new shear model is proposed using ORLTs in accordance with plate buckling theory and previously developed formulas for predicting the shear strength of SBCWs. The proposed ORLT models are implemented using the regression learner toolbox of MATLAB software (2020b). The available data of more than 125 test results from different specimens prepared by previous researchers are used to create the model. In this study, web geometry and relevant web steel grades determine the shear capacity of SBCWs. Four regression methods are adopted. Results are compared with those of an artificial neural network model. The model output factor represents the ratio of the web vertical shear stress to the normalised shear stress. Shear capacity can be estimated on the basis of the resulting factor from the model. The proposed model is verified using two methods. In the first method, a series of tests are performed by the authors. In the second method, the results of the model are compared with the shear values obtained experimentally by other researchers. On the basis of the test results of previous studies and the current work, the proposed model provides an acceptable degree of accuracy for predicting the shear capacity of SBCWs. The results obtained using Gaussian process regression are the most appropriate because its recoded mean square error is $0.07 \%$. The proposed model can predict the shear capacity of SBCWs with an acceptable percentage of error. The recoded percentage of error is less than $5 \%$ for $93 \%$ of the total specimens. By contrast, the maximum differential obtained is $\pm 10 \%$, which is recorded for 3 out of 125 specimens.
\end{abstract}

Keywords: shear strength; corrugated web; regression learner techniques; steel beams

\section{Introduction}

Extensive studies have been conducted regarding the shear strength (SS) of steel beams with trapezoidal corrugated webs (SBCWs). This section presents some of these studies. An experimental study was conducted by Lindner and Aschinger [1] to calculate the SS of SBCWs. They suggested using 70\% of shear buckling stress as the nominal SS for designing SBCWs. Worthy experimental and analytical research conducted by Elgaaly et al. [2], using loaded predominantly in shear. Large-scale SBCW investigations were conducted by Sause et al. [3], Abbas [4] and Driver et al. [5] to estimate the SS of SBCWs. They provided an equation for estimating the lower bound of the SS of SBCWs. In addition, they recommended precluding global buckling because this phenomenon requires a significant loss of strength and a low degree of post-buckling strength. Yi et al. [6] presented a formula for the nominal SS of SBCWs. This formula was validated by comparing the obtained values 
of 15 test results and finite element analysis results. Moon et al. [7] reported the results of three tests and described the SS formula presented by Yi et al. [6]. Moon et al. [7] compared the results of their proposed formula with the results of several formulas developed by other researchers from 17 tests. Sause and Braxtan [8] theoretically investigated the SS of SBCWs. They collected a database of 102 tests from 8 previous studies and developed an analytical model for estimating the normalised SS. Their formula was consistent with only one subset (i.e., 22 test results) of the 120 available published test results. These researchers attributed the inconsistency to the test conditions. Consequently, their proposed model was valid only for SBCWs that fulfil the geometric criteria they set. From the previous research, numerous buckling formulas have been proposed to calculate global shear buckling and interaction buckling (IB). The proposed formulas for calculating IB were given by [6,8-13] from 1984 to 2008. Regarding the hybrid steel beams with corrugated web, Elamary et al. [14] presented an experimental study concerned with the failure mechanism of SBCW's non-welded inclined fold. The case of non-welded inclined folds, owing to decrease the effect of the fatigue cracks initiated along the inclined folds. Additionally, they studied the influence of using a limited number of flange stiffeners at certain places to postpone the earlier flange buckling that may occur in these places.

Extensive research was conducted and focus on the computational methods and their uses for validating experiments; some of it is presented herein, which carried out by [15-20]. Manoj et al. [15] studied the flexural behaviour of steel beams by using ANSYS software. They reported that the load-carrying capacity of the CW beam increased by increasing the web thickness as well as the optimum corrugated angle is recommended to be $45^{\circ}$. Krejsa et al. $[16]$ and Čajka et al. $[17,18]$ discussed an application of the original and probabilistic method- "Direct Optimized Probabilistic Calculation"—as a faster completion method of computations. They used this approach for modelling and experimental validation of reliability in the pre-stressed masonry construction.

Research on the shear capacity of SBCW calculation by using optimised regression learner techniques (ORLTs) is limited. The only previous study that used regression techniques in SBCWs was that by Barakat et al. [21] in 2015. They proposed a model for predicting the shear buckling strength of SBCWs. The model calculation was based on the calculated interaction shear buckling of the specimen. They collected 93 experimental data from previous studies. These researchers concluded that the accurate prediction of the shear buckling strength of SBCWs was within a 95\% confidence interval when minimal processing of data was performed.

The problem is that using some input parameters representing web dimensions and properties can contribute to a qualitatively higher level of the reliability assessment in computing the shear capacity of SBCWs. For this reason, the current study presents an alternative method for calculating the maximum shear capacity of SBCWs by using ORLTs through the known dimensions and steel grade of specimen webs. The model considers only web material properties and dimensions as major factors in the calculation without determining local, global and interaction shear buckling. The advantage of this model is that it requires extremely limited input data (i.e., web dimension and steel grade). In addition, the result obtained from the model parameters considers the interaction amongst various shear failure modes (i.e., local, global and interaction).

The objective of this research is to propose such a model that can predict the shear capacity of SBCWs computationally by using the steel grade and dimensions of a web determined from the preliminary design. The input data required for the model are web dimensions (thickness, height, shear span and corrugation geometric profile) and web yield stress. The resulting factor from the model represents the ratio of the web vertical shear stress to the normalised shear stress. The maximum shear capacity of the beam can be regarded as the model's resulting factor multiplied by the normalised shear strength multiplied by the yielding vertical shear force. The research procedure can be summarised in seven steps. (1) Data relevant to more than 125 experimentally tested specimens are collected from the published studies of other researchers. (2) Test data and results from 
previous studies are organised in accordance with the corresponding parameters of the test specimens. (3) A summary of previously proposed formulas for predicting the SS of SBCWs with their corresponding theories is presented to identify the most dominant parameter that influences the SS of SBCWs. (4) The regression learner toolbox of MATLAB software is used for the regression process, which adopts four major optimised regression methods: decision tree (DT), support vector machines (SVM), Gaussian process regression (GPR) and ensemble trees (EN). Each regression method has different parameters obtained from the optimisation process. (5) The four ORLTs are tested by comparing the mean square error (MSE) and root-mean-square error (RMSE) calculated for each method. (6) In addition, another comparison is conducted between the results obtained from each of the four methods with that obtained from an artificial neural network (ANN) model. (7) Validation of the new modelling technique is achieved in two ways. Firstly, an experimental programme is conducted to test three specimens with different web geometries, steel grades and load setups. Secondly, the model results are compared with the test results obtained from two previous studies.

\section{Theoretical Background}

The local shear buckling stress of a corrugated web can be predicted in accordance with plate buckling theory [22]. Equation (1) expresses the corresponding local elastic shear buckling stress, $\tau_{L, e l}$, on a single fold (longitudinal or inclined, Figure 1 ). In this case, each fold is assumed to be supported by the adjacent folds along its vertical edges and by the flanges along its horizontal edges.

$$
\tau_{e l, L}=k_{L} \frac{\pi^{2} E}{12\left(1-v^{2}\right)\left(\omega / t_{W}\right)^{2}}
$$

where, $k_{L}$ is the local shear buckling coefficient that depends on the fold aspect ratio and the boundary conditions; $E$ and $v$ are Young's modulus and Poisson's ratio, respectively; $w$ is the fold width; $t_{w}$ is the web thickness. To determine the smallest value of $\tau_{L, e l}, w$ is set to be larger than $c$ and b, as illustrated in Figure 1. Equation (1) has been used in many studies $[1,2,4-6,23]$ to predict the local elastic shear buckling stress of corrugated webs.

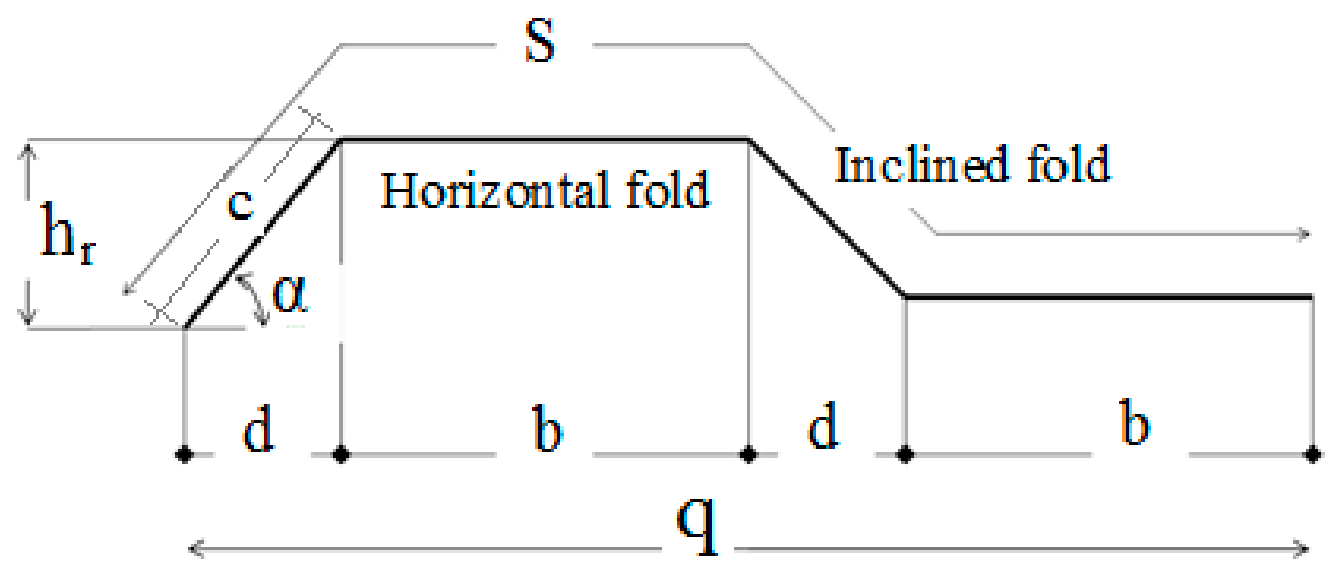

Figure 1. Corrugated web: profile configuration.

On the basis of the expression for the global elastic shear buckling stress $\tau_{G, e l}$ of corrugated plates proposed by Easley [24], Abbas [25] developed an equation to express the global shear buckling stress from geometric properties, i.e., Equation (2).

$$
\tau_{G, e l}=k_{G} F(\alpha, \beta) \frac{E t_{W}^{1 / 2} b^{3 / 2}}{12 h_{w}^{2}}
$$


where $F(\alpha, \beta)$ is a relation between coefficient $(\beta)$ and corrugation profile slope $(\alpha) ;(\beta)$ is a coefficient based on the relation between the ratio of $\mathrm{b}$ to $\mathrm{c}$ and the corrugation profile slope $(\alpha)$. This relation is proposed in Equation (3).

$$
F(\alpha, \beta)=\sqrt{\frac{(1+\beta) \sin ^{3} \alpha}{\beta+\cos \alpha}}\left\{\frac{3 \beta+1}{\beta^{2}(\beta+1)}\right\}
$$

where, $h_{w}$ and $t_{w}$ are the web height and thickness, respectively.

To minimise $k_{L}$, a small aspect ratio, $w / h w$, must be considered. In this case, $k_{L}$ lies between 5.34 and 8.98, assuming simply supported and fixed edges, respectively. In addition, a minimised $k_{G}$ can be obtained by assuming that the web is infinitely long [8]. By assuming that the web is long relative to hw, Elgaaly et al. [2] suggested in 1996 that $k_{G}$ should be set as 31.6 or 59 (assuming that the web is simply supported by flanges or flanges provide the web with fixed support, respectively). However, Easely [24] suggested in 1975 that $k_{G}$ varies between 36 and 68.4.

The general IB shear stress formula originally proposed by Lindner and Aschinger [1] is given in Equation (4).

$$
\frac{1}{\left(\tau_{l, \mathrm{el}}\right)^{n}}=\frac{1}{\left(\tau_{L, \mathrm{el}}\right)^{n}}+\frac{1}{\left(\tau_{G, \mathrm{el}}\right)^{n}}
$$

where, $\tau_{I, e l}, \tau_{L, e l}$ and $\tau_{G, e l}$ are interaction, local and global elastic shear buckling stresses.

Corresponding to Equation (4), Lindner and Aschinger [1] proposed two interaction formulas with $n=1$ and $n=2$. Yi et al. [6] used a formula that corresponds to Equation (4) with $n=1$. Equation (4) is solved for $\tau_{I, e l}$, as shown in Equation (5).

$$
\tau_{l, n, \mathrm{el}}=\frac{\tau_{L, \mathrm{el}} \tau_{G, \mathrm{el}}}{\left[\left(\tau_{L, \mathrm{el}}\right)^{n}+\left(\tau_{G, \mathrm{el}}\right)^{n}\right]^{1 / n}}
$$

On the basis of local, global and interaction buckling shear stresses, local, global and interaction buckling slenderness ratios can be, respectively, expressed as follows:

$$
\begin{gathered}
\lambda_{L}=\sqrt{\frac{\tau_{y}}{\tau_{\mathrm{el}, L}}}=\frac{\omega}{t_{w}} \sqrt{\frac{12\left(1-v^{2}\right) \tau_{y}}{k_{L} \pi^{2} E}}, \\
\lambda_{G}=\sqrt{\frac{\tau_{y}}{\tau_{\mathrm{el}, G}}}=\sqrt{\frac{12 \tau_{y} h_{w}^{2}}{k_{G} F(\alpha, \beta) E t_{w}^{1 / 2} b^{3 / 2}}}, \\
\lambda_{l, n}=\sqrt{\frac{\tau_{y}}{\tau_{l, n, e l}}}=\lambda_{L} \lambda_{G}\left[\left(1 / \lambda_{L}\right)^{2 n}+\left(1 / \lambda_{G}\right)^{2 n}\right]^{1 / 2 n} .
\end{gathered}
$$

where $\lambda_{L}, \lambda_{G}$ and $\lambda_{I, n}$ are local, global and interaction buckling slenderness ratios; whereas, the $\tau_{y}$ is shear yield stress, and $\tau_{I}$ is the interaction shear buckling. Numerous studies have used these slenderness ratios to calculate the normalised local, global and interaction elastic shear buckling strength. The following formula was proposed by Yi et al. [6] for calculating normalised shear strength $\left(\rho_{n, Y}\right)$ :

$$
\begin{gathered}
\rho_{n, Y}=\frac{\tau_{n, Y}}{\tau_{Y}}=1-0.614\left(\lambda_{l, 1}-0.6\right) \leq 1.0 \text { if } \lambda_{l, 1} \leq \sqrt{2}, \\
\rho_{n, Y}=\frac{\tau_{n, Y}}{\tau_{Y}}=\frac{1}{\left(\lambda_{l, 1}\right)^{2}} \text { if } \lambda_{l, 1}>\sqrt{2},
\end{gathered}
$$

where $\rho_{n, Y}$ is the normalised shear strength proposed by YI et al. [6]; $\lambda_{l, 1}$ is derived from Equation (8) with $n=1 ; \tau_{Y}$ is the shear yield stress, which is equal to $\frac{F_{Y}}{\sqrt{3}}$. 


\section{Assessment of SBCW Shear Capacity Formulas}

In accordance with previous studies and theories, maximum shear capacity can be largely determined from the contribution of the web. Therefore, the proposed formula is based on the calculated local, global and IB shear stresses for each specimen from Equations (6)-(8). Assume that web shear stress is constant over web height and equal to the average calculated shear stress. Hence, the web vertical shear stress can be calculated using Equation (10) as reported by [8].

$$
\tau=\frac{v_{n}}{h_{w} t_{w}},
$$

where $V_{n}$ is the nominal vertical shear force in the steel beam.

Assume that $(\zeta)$ represents the ratio of the web vertical shear stress $(\tau)$ to the normalised shear stress $\left(\tau_{n, Y}\right)$ as indicated in Equation (11) as reported by [8].

$$
\zeta=\frac{\tau}{\tau_{n, Y}}
$$

Accordingly, from Equations (9)-(11), the following formula is proposed by the author to calculate the normalised shear force $\left(V_{n}\right)$ (i.e., maximum shear capacity of a test specimen), and it is equal.

$$
V_{n}=\zeta \rho_{n, Y} \frac{F_{Y}}{\sqrt{3}} h_{w} t_{w}
$$

where $\left(\rho_{n, \gamma}\right)$ is the normalised shear strength, and $(\zeta)$ is the ratio factor previously defined in Equation (11).

\section{Test Data}

The current study presents the database of 122 SS tests collected from 13 published studies [1,2,7,26-31]. This database is divided into two groups. The first group contains 115 published sources used in creating ORLT models. The second group consists of five shear tests collected from $[32,33]$. The group with three shear tests conducted by the authors is used to validate the model.

\subsection{Test Data Published by Other Researchers}

The published test data are listed in Tables A1-A9 (Appendix A). The dimensions of the test specimens are provided in Tables A1-A9. These tests were conducted by the following authors. In 1996, Elgaaly et al. [2] reported the results of 42 tests (Table A1). The results of 25 tests from Sweden, Germany and Finland were reported by Lindner and Aschinger [1] in 1998 (Table A2). Johnson and Cafolla [26] summarised the results of three specimens in 1997 (Table A3). The results of 20 specimens were tested under shear forces by Peil [27] in 1998 (Table A4). Driver et al. [5] presented the shear test results of two steel girders with corrugated webs in 2002 (Table A5). Lee et al. [28] reported the results of nine shear tests in 2003 (Table A6). Moon et al. [7] summarised the results of three shear tests in 2008 (Table A7). Moussa et al. [29] provided the results of nine tests in 2018 (Table A8). Wang et al. [30], Sause and Clarke [23] and Hannebauer et al. [31] reported the results of one test each in 2019 (Table A9). In these tables, the definitions of symbols $h_{w}, b_{p}, t_{w}, b, d, h_{r}$ and $F_{y}$ are the same as those given earlier; whereas $h_{w} / t_{w}$ is the web slenderness. From a previous study [6], a conclusion is drawn that the normalised SS exhibits an indirect relation with the slenderness interaction shear buckling strength. Therefore, for all the test specimens listed in Tables A1-A9, Figure 2 shows the normalised experimental SS $\rho_{e}=\tau_{e} / \tau_{y}$ versus the interaction slenderness ratio at $\mathrm{n}=1\left(\lambda_{I, 1}\right)$. The comparison between the normalised SS proposed by Yi et al. [6] $\left(\rho_{n, Y}\right)$ and the normalised experimental SS is illustrated in Figure 2. The horizontal axis in this figure represents the slenderness interaction shear buckling strength with the exponent $n=1$. As shown in this 
figure, the major factors that affect shear capacity are web height, web panel, web thickness, corrugation geometry and web yield stress.

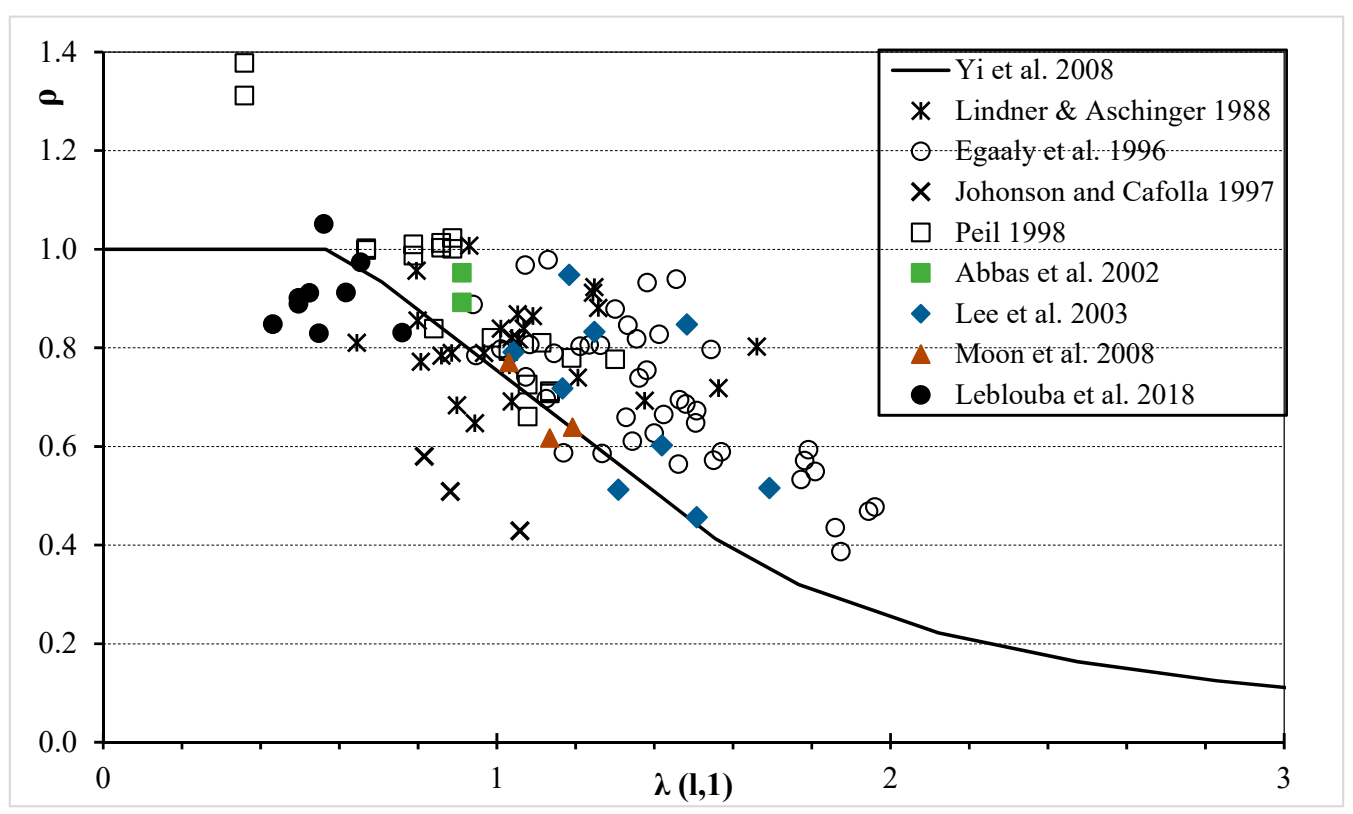

Figure 2. Relation between slenderness interaction shear buckling strength and normalised experimental shear strength.

\subsection{Test Data from the Authors}

To validate the model, a series of three tests were conducted on SBCWs with different properties, dimensions and load cases (Figure 3). The load cases and dimensions of the test beams, which are denoted as 3PCW350, 4PCW275 and 3PCW200, and the material yield strength are provided in Table 1 . In this table, ' $\mathrm{P}$ ' and ' $\mathrm{CW}$ ' represent 'point load' and 'corrugated web,' respectively; the number before ' $\mathrm{P}$ ' represents the number of line loads applied. Meanwhile, the number following ' $\mathrm{CW}$ ' indicates horizontal fold (HF) length (in $\mathrm{mm}$ ). All the specimens were simply supported and loaded on a hydraulic testing machine by applying displacement control techniques at the civil engineering laboratories of Taif University. Specimens 3PCW350 and 3PCW200 have an HF of $350 \mathrm{~mm}$ and $200 \mathrm{~mm}$, respectively. The two specimens have the same web yield stress and tested under a threepoint load, as shown in Figure 3a,c. Specimen 4PCW275 has an HF of $275 \mathrm{~mm}$ and different yield stresses. It was tested under a four-point load as shown in Figure 3b. The three specimens analogised one another in the inclined fold dimensions and corrugation angle.

Table 1. Test data from the authors.

\begin{tabular}{|c|c|c|c|c|c|c|c|c|c|}
\hline \multirow{2}{*}{ Specimen ID } & \multirow{2}{*}{$h_{w}(\mathrm{~mm})$} & \multirow{2}{*}{$\mathrm{a}(\mathrm{mm})$} & \multirow{2}{*}{$t_{w}(\mathrm{~mm})$} & \multicolumn{3}{|c|}{$\begin{array}{c}\text { Corrugation } \\
\text { Dimensions (mm) }\end{array}$} & \multirow{2}{*}{$\begin{array}{l}F_{y w} \\
\mathrm{MPa}\end{array}$} & \multirow{2}{*}{$\begin{array}{c}\text { Web } \\
\text { Slenderness }\end{array}$} & \multirow{2}{*}{ Variables } \\
\hline & & & & $b$ & $h_{r}$ & $d$ & & & \\
\hline 3PCW350 & 384 & 900 & 2.80 & 350 & 100 & 100 & 325 & 137.14 & $b$, Load \\
\hline 4PCW275 & 384 & 750 & 3.00 & 275 & 100 & 100 & 357 & 128.00 & $a, t_{w}, F_{y w}$ \\
\hline 3PCW200 & 384 & 900 & 2.80 & 200 & 100 & 100 & 325 & 137.14 & $b$, Load \\
\hline
\end{tabular}




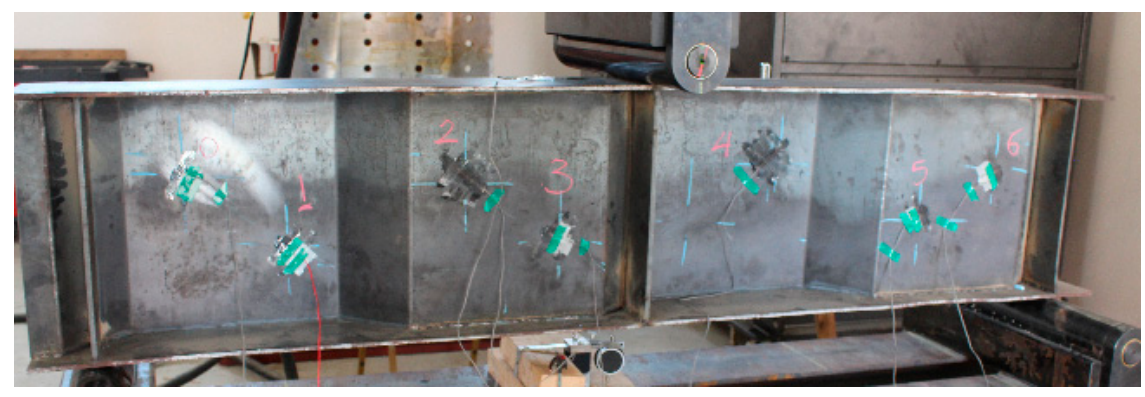

(a)

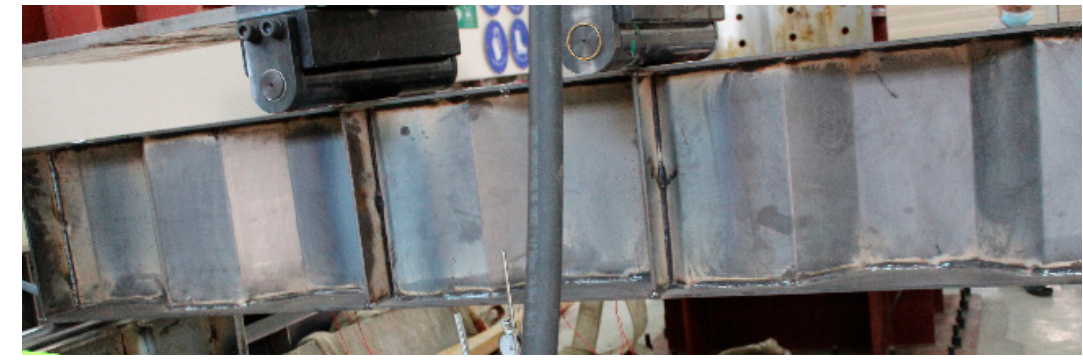

(b)

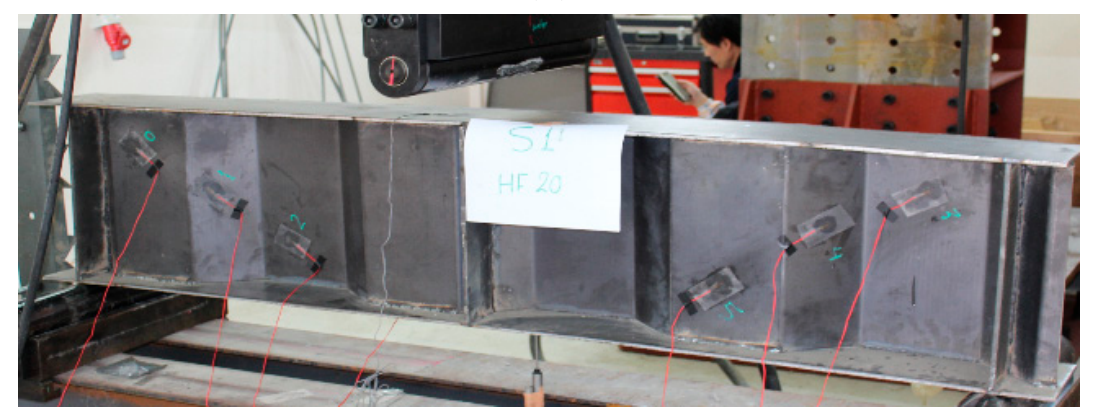

(c)

Figure 3. Sample of SBCW specimens: (a) Specimen 3PCW350, (b) Specimen 4PCW275 and (c) Specimen 3PCW200.

\subsection{Test Setup}

The specimens were tested at Taif University in Saudi Arabia by using a $2000 \mathrm{kN}$ capacity test frame, as shown in Figure 4 . The specimens were tested under different loading conditions (three- and four-line loads). The unbraced length of the compressive flange was $1800 \mathrm{~mm}$ and $2250 \mathrm{~mm}$ for the three- and four-line loads, respectively, in accordance with the locations of the supports. The total length of a specimen was longer than the unbraced length of the compression flange by $100 \mathrm{~mm}$ (50 $\mathrm{mm}$ from each side). The shear span for the three-line loads was $900 \mathrm{~mm}$, and for the four-line loads was $750 \mathrm{~mm}$. The primary objective for fabricating and testing the specimens was to validate the proposed model under variable parameters and not to compare it with each other. The parameters were different for each specimen, such as HF length, loading type, shear span, web thickness and web yield stress. The specimens were loaded using displacement control techniques with an increment of $0.005 \mathrm{~mm} / \mathrm{s}$. To measure the vertical deflections of the specimens, a linear variable differential transformer (LVDT) was installed under the mid-span of each specimen, as illustrated in Figure 4. 


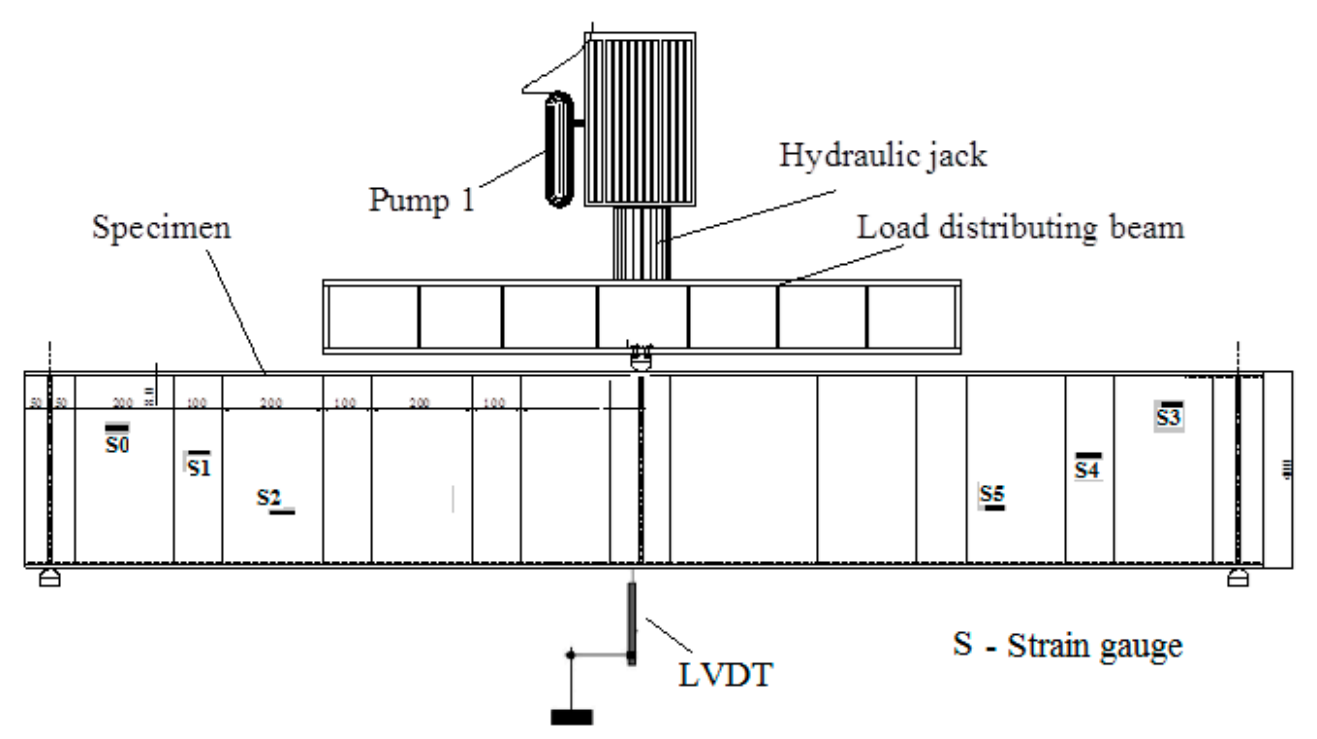

Figure 4. Test scheme.

The fabricated specimens had the same flange material properties and dimensions, whilst the webs had different material and geometric (HF length and thickness) properties. For all the specimens, the web slenderness ratio belongs to Class 4 in accordance with the Eurocodes. From the test results, the plot of the vertical load versus the mid-span vertical deflection of each tested specimen is shown in Figure 5. The maximum deflections achieved by the three-line load specimens (3PCW200 and 3PCW350) were $3.8 \mathrm{~mm}$ and $5 \mathrm{~mm}$, respectively, before failure. Meanwhile, the maximum deflection recorded for specimen 4PCW275 was nearly $6 \mathrm{~mm}$. Specimen 4PCW275 exhibited lower initial stiffness than the two specimens subjected to three-line loads. Conversely, the maximum shear force sustained by Specimen 4PCW275 $(147.50 \mathrm{kN})$ was higher than those of the three-line load specimens, i.e., 3PCW200 $(117.5 \mathrm{kN})$ and 3PCW350 $(105 \mathrm{kN})$. Such difference is attributed to the four-line load specimen having higher web thickness and web yield stress than the three-line load specimens. This result is reasonable because web thickness and web yield stress are the most dominant parameters that influence the shear capacity of SBCWs.

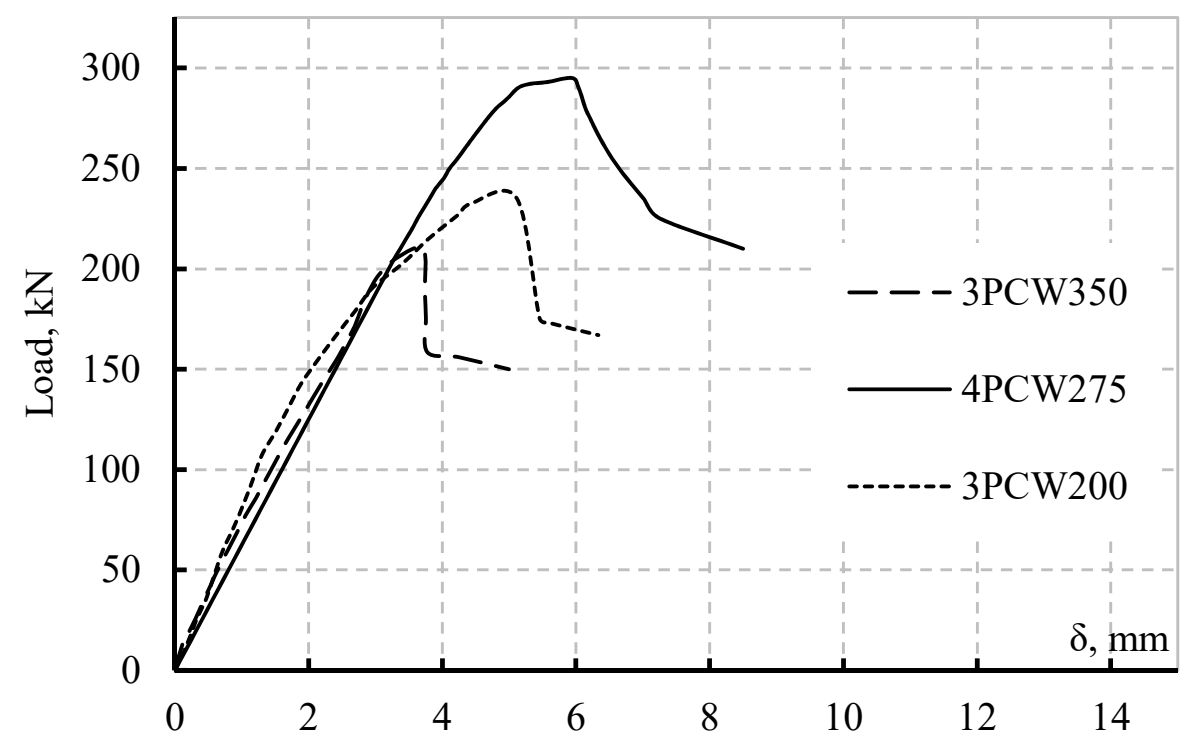

Figure 5. Load deflection curves of the specimens. 


\section{ORLTs}

The regression learner toolbox of MATLAB software is one of the most frequently used techniques for regression. It has four major optimised regression methods [34]: DT, SVM, GPR and EN. Each regression has different parameters obtained from the optimisation process. For example, the SVM hyperparameter search range is selected as follows: box constraints varied from 0.001 to 1000 ; the kernel scale varied from 0.001 to 1000; epsilon varied from 0.00030022 to 30.0222; the kernel functions were Gaussian, linear, quadratic, and cubic; the standardised data were true and false [34]. The optimal parameters of each ORLT were determined and evaluated based on the Bayesian optimisation (BO) technique [35-37]. The acquisition function used in the optimisation process was an expected improvement per second plus, and the total number of iterations was 30 . The BO technique is the most effective approach used to determine the hyperparameters of the ORLTs during the training stage [35]. The $\mathrm{BO}$ technique determines the optimal parameters of each regression technique during each training step based on the prior and the probability space value of each parameter and choosing the highest probability values used to enhance the predicting accuracy of the ORLT model [36]. The details determining the best parameters of each regression technique using the $\mathrm{BO}$ technique were presented in [36] and [37].

The input features of the dataset samples were firstly normalised before the training process, as follows:

$$
x_{i}=\frac{x_{i}-M I N_{i}}{M A X_{i}-M I N_{i}}, i=1,2, \ldots ., 8,
$$

where $x_{i}$ is the $i$ th input feature; $M I N_{i}$ and $M A X_{i}$ are the minimum and maximum values of the $i$ th input feature, respectively.

Figure 6 introduces the training procedure of ORLTs by using MATLAB's regression learner toolbox in 2020b MATLAB/Software.

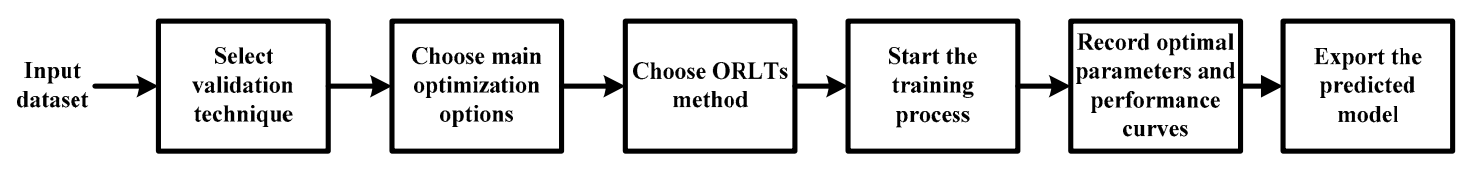

Figure 6. Training procedure of ORLTs.

The training procedure of the ORLTs can be summarised as follows:

1. The validation technique was selected, the cross-validation technique with 10 folds was chosen before the training process.

2. The primary optimisation options were selected, and the option used was the BO technique, with an expected improvement per second plus and 30 iterations.

3. One of the ORLTs was selected (DT, SVM, GPR or EN).

4. The training process is started to determine the optimal parameters and predicted model of this method.

5. The optimal parameters and performance model of the selected method were recorded.

6. Finally, the ORLT model of the selected method was exported to be used in the prediction of the original and new datasets.

Figure 7a presents the minimum MSE versus the training iteration numbers of DT, SVM, GPR and EN during training. The MSE values of the four regression methods illustrated that GPR achieved the lowest MSE amongst the four methods. Meanwhile, DT exhibited poor training performance. Figure $7 \mathrm{~b}$ illustrates the relation between the predicted responses versus the true responses of the four regression methods. GPR exhibited the best response amongst the four methods.

Table 2 provides the optimal parameters of the four ORLT models. For example, the optimal parameters of the EN model are as follows: the selected ensemble method is the bag; the number of learners is 57 ; the minimum leaf size is 2; the number of predictors to samples is 8 . The optimal parameters of the DT, SVM and GPR models are listed in Table 2. 


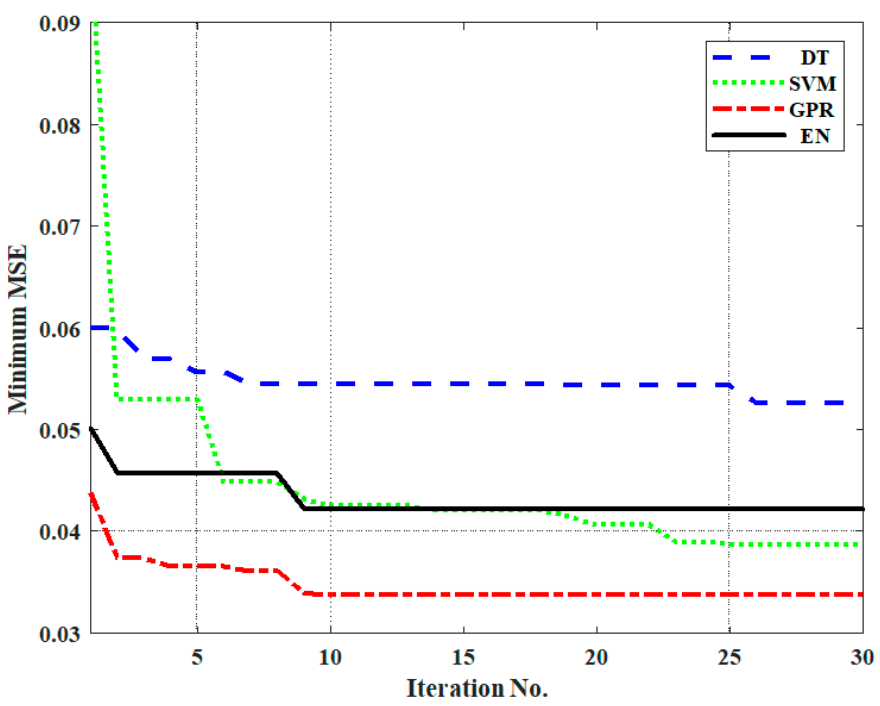

(a)
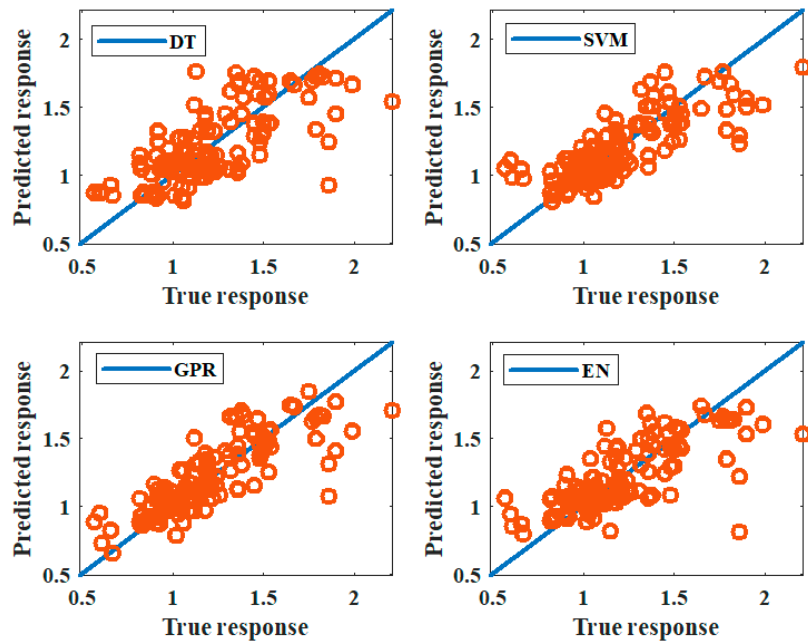

(b)

Figure 7. (a) Minimum MSE vs. iteration number; (b) predicted response vs. true response during training.

Table 2. Optimal parameters of each ORLT.

\begin{tabular}{cc}
\hline ORLTs & Optimal Parameters \\
\hline DT & Minimum leaf size: 12 \\
\hline & Box constraints: 992.584 \\
SVM & Epsilon: 0.00031804 \\
& Sernel function: Linear \\
& Sigma: 0.16623 \\
GPR & Basis function: Zero \\
& Kernel function: Isotropic exponential \\
& Kernel scale: 0.66404 \\
& Standardised data: True \\
\hline & Ensemble method: Bag \\
EN & Number of learners: 57 \\
& Minimum leaf size: 2 \\
& Number of predictors to samples: 8 \\
\hline
\end{tabular}




\section{Model Validation and Comparison}

The four ORLTs were tested and validated by comparing the calculated ratio for each specimen (ratio of web vertical shear stress to normalised shear stress) with that obtained from an ANN. MATLAB's ANN toolbox was used to train and test the ANN model. The normalised dataset (120 samples) was used as input for the ANN, and the corresponding ratio of web vertical shear stress $(\tau)$ to normalised shear stress $\left(\tau_{n, Y}\right)$ (Equation (11)) was used as the output for the training stage of the ANN. The ANN model consisted of three layers: the input, hidden and output layers. The number of neurons in the input layer was equal to the number of input features (eight input layers). The number of neurons in the hidden layer was selected to enhance the performance of the ANN model (24 neurons were used here). The number of output layers is equal to the number of output variables (one layer is used here). The normalised 120 dataset samples were divided during the training stage of the ANN model into three sets: for training ( 84 samples, $70 \%$ ), validation (18 samples, $15 \%$ ) and testing (18 samples, 15\%). The MSE performance of the ANN model and the predicted responses for the training, validation and testing sets are presented in Figure 8.

Table 3 provides the MSE and RMSE of the differences between the values of $\zeta$ estimated using the model and calculated theoretically from the test database using Equation (11). From the results in Table 3, the authors concluded that GPR is the most suitable and accurate method for estimating the ratio $\zeta$ with an acceptable degree of accuracy.

Table 3. Comparison of the ORLT models with the ANN model.

\begin{tabular}{cccccc}
\hline $\begin{array}{c}\text { Evaluation } \\
\text { Techniques }\end{array}$ & DT & SVM & GPR & EN & ANN \\
\hline MSE & 0.04212 & 0.03962 & 0.00074 & 0.00391 & 0.01088 \\
RMSE & 0.20522 & 0.19906 & 0.02723 & 0.06253 & 0.10432 \\
\hline
\end{tabular}

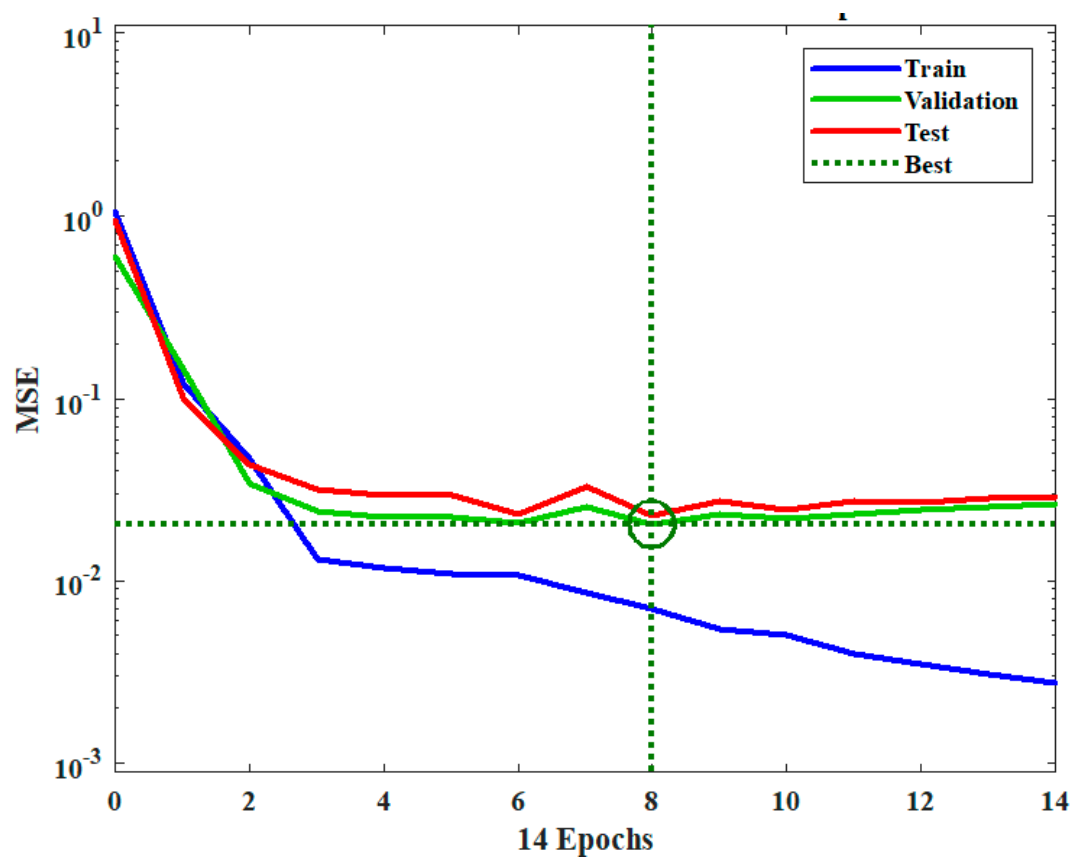

(a)

Figure 8. Cont. 

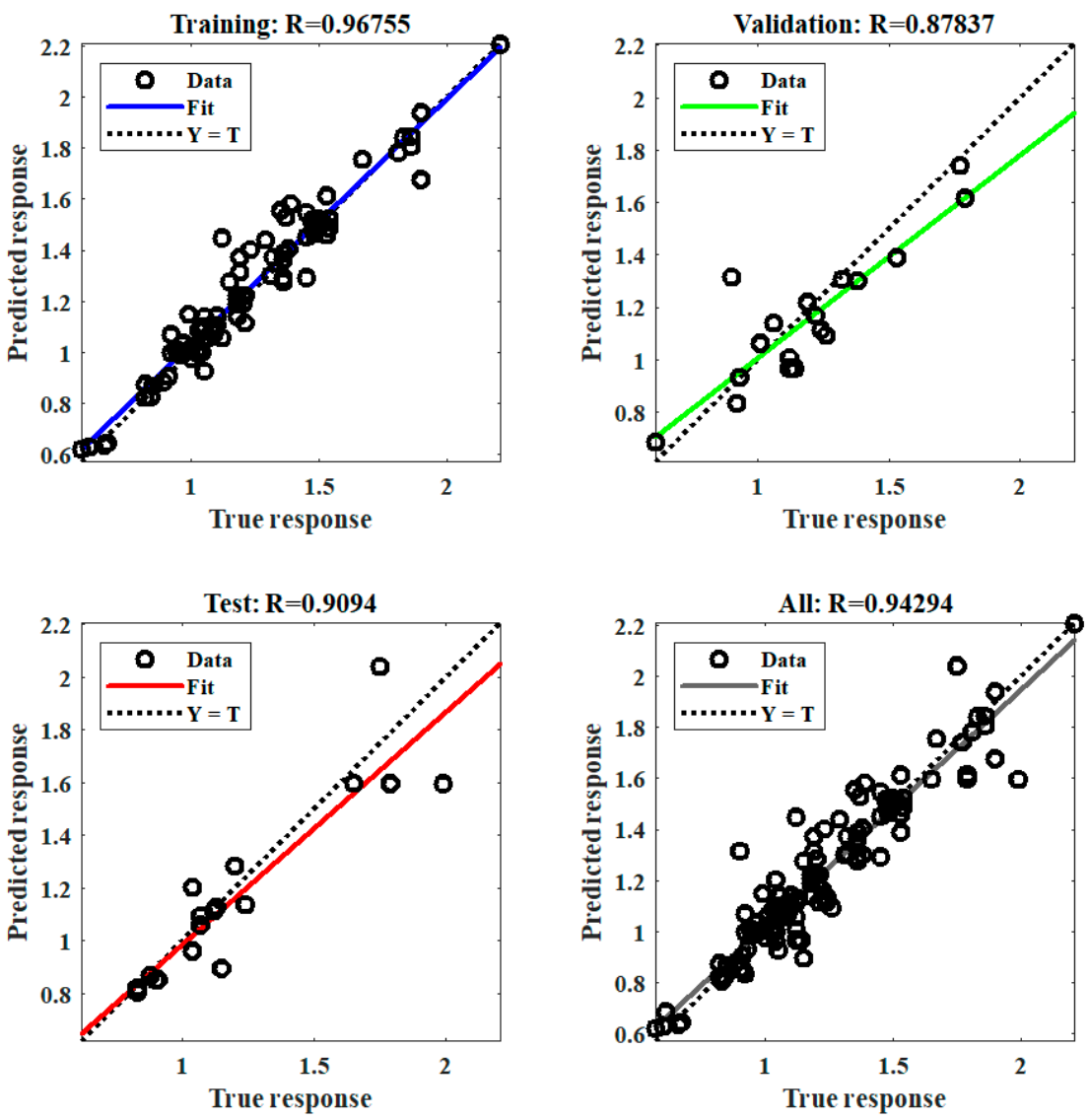

(b)

Figure 8. Validation and testing sets: (a) MSE vs. iteration epochs and (b) predicted response vs. true response.

\section{Initial Comparison with Published Experimental Data}

The analysis of the test results of the test specimens is presented in Appendix A (Tables A10-A18). A specimen identifier is given in the first column, and the local slenderness ratio is provided in the second column. The third column presents the global slenderness ratio, and the fourth column shows the interaction slenderness ratio $\lambda_{I, 1}$ [Equation (8), with $\mathrm{n}=1$ ]. The fifth column provides the normalised SS from Equation (9), $\rho_{n, Y}$. The sixth column lists the values of $\zeta$ calculated using GPR. The seventh column gives the anticipated maximum shear force $\left(V_{n}\right)$ by using Equation (12), whilst the eighth column provides the shear test results $\left(V_{T}\right)$. The last column indicates the ratio of $V_{n}$ to $V_{T}$.

Table 4 provides a summary of the results divided into three groups. The first group represents the results of 76 specimens. The number of specimens in this group is equivalent to $65 \%$ of the total number, and the results of shear forces from the proposed model are between $\pm 1 \%$ of the test shear results. The second group represents the results of 38 specimens, which is equivalent to $32 \%$ of the total number of collected specimens. The maximum shear force calculated in Group 2 by using the proposed model is $\pm 5 \%$ of the corresponding specimen's test shear results. The last group included three specimens, which is equivalent to nearly $3 \%$ of the total. The maximum shear forces anticipated by the model exhibit $-8 \%$ to $10 \%$ of the corresponding specimen's test shear results.

To validate the proposed model, the database of six tests from two previous studies and three tests conducted by the authors were presented in this paper. Table 5 provides the dimensions of the test specimens from the following studies: Moussa et al. [32] reported the results of four tests, and Nie et al. [33] summarised the results of two specimens. The database of the three tests conducted by the authors is presented in Table 1. 
Table 4. Mean, standard deviation (Std. dev.), coefficient of variation (Co. Var.), maximum (Max.) and minimum (Min).

\begin{tabular}{cccccc}
\hline Number of Test Data & Mean & Std. Dev. & Co. Var. & Max. & Min. \\
\hline 116 & 1.0018 & 0.021 & 0.021 & 1.10 & 0.926 \\
76 out of $116(65 \%)$ & 0.987 & 0.015 & 0.015 & 1.015 & 0.986 \\
38 out of $116(32 \%)$ & 1.0033 & 0.029 & 0.028 & 1.055 & 0.955 \\
3 out of $116(3 \%)$ & 1.0185 & 0.071 & 0.07 & 1.10 & 0.926 \\
\hline
\end{tabular}

Table 5. Data of specimens tested in previous studies.

\begin{tabular}{|c|c|c|c|c|c|c|c|c|}
\hline \multirow{2}{*}{ Specimen ID } & \multirow{2}{*}{$h_{w}$} & \multirow{2}{*}{ a } & \multirow{2}{*}{$t_{w}$} & \multicolumn{3}{|c|}{ Corrugation Dimensions } & \multirow{2}{*}{$F_{y w}$} & \multirow{2}{*}{$\begin{array}{c}\text { Web } \\
\text { Slenderness }\end{array}$} \\
\hline & & & & $b$ & $h_{r}$ & $d$ & & \\
\hline \multicolumn{9}{|c|}{ Moussa et al. [32] } \\
\hline A12-305-30 & 305 & 557.0 & 1.20 & 40 & 20.00 & 34.64 & 230 & 254.17 \\
\hline A12-410-30 & 410 & 557.0 & 1.20 & 40 & 20.00 & 34.64 & 230 & 341.67 \\
\hline A12-505-30 & 505 & 557.0 & 1.20 & 40 & 20.00 & 34.64 & 230 & 420.83 \\
\hline A12-505-45 & 505 & 526.5 & 1.20 & 40 & 28.28 & 28.28 & 230 & 420.83 \\
\hline \multicolumn{9}{|c|}{ Nie et al. [33] } \\
\hline S2-1 & 260 & 1200 & 0.90 & 80 & 48 & 64 & 385.50 & 288.89 \\
\hline S2-2 & 360 & 1200 & 0.90 & 80 & 48 & 64 & 385.50 & 400.00 \\
\hline
\end{tabular}

By using the preceding data as a database for the proposed model, the maximum capacity of the shear force that can be resisted by each specimen is provided in Table 6 . The ratio of the model results to the experimental results is $\pm 9 \%$.

Table 6. Analysis results of test specimens reported in previous studies.

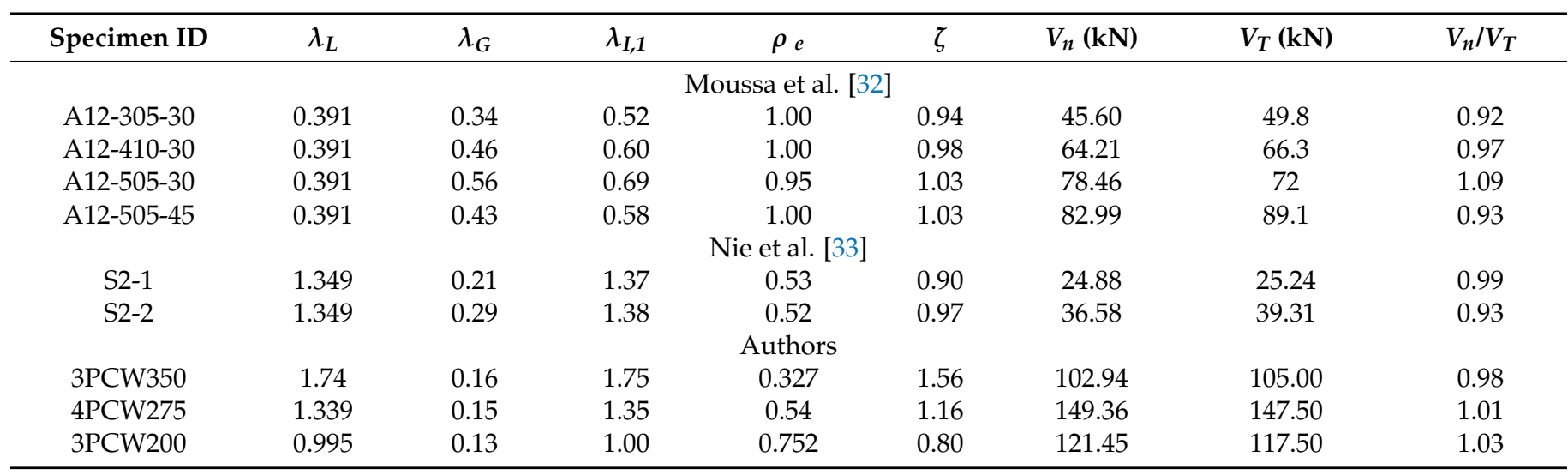

\section{Conclusions}

This study presented a new approach for calculating the maximum shear capacity of SBCWs. The approach was implemented using ORLTs. Four regression methods were used to select the most appropriate one, which could achieve the least MSE. The model was created on the basis of 125 test results of different specimen parameters obtained by previous researchers. The input parameters were the web dimensions (thickness, height, shear span and corrugation geometric profile) and web yield stress. The model output was the ratio of the web vertical shear stress to the normalised shear stress. Validation of the model results was determined using both an experimental programme conducted by the authors and an experimental database from previous studies. The following conclusions can be drawn from the obtained results: (i) The model procedures to calculate the maximum shear capacity of steel beams with corrugated web are well-suited for the design of beam elements in load-carrying with the required level of reliability. (ii) The shear capacity of SBCWs can be predicted to an acceptable degree of accuracy by using the resulting factor 
from the proposed model. (iii) The proposed model exhibited a percentage error on the shear capacity of less than $\pm 5 \%$ for $97 \%$ of the total number of specimens. (iv) ORLTs methods can be used in calculating the design shear of SBCWs. (v) The most appropriate method for calculating the shear force of SBCWs is the GPR method. (vi) The mean square error (MSE), as the difference between the resulting output factors and those calculated for each specimen, was less than $0.1 \%$.

Author Contributions: Conceptualisation, A.S.E. and I.B.M.T.; methodology, A.S.E. and I.B.M.T.; software, I.B.M.T.; validation, A.S.E. and I.B.M.T.; formal analysis, A.S.E. and I.B.M.T.; investigation, A.S.E. and I.B.M.T.; resources, A.S.E. and I.B.M.T.; data curation, A.S.E.; writing-original draft preparation, A.S.E. and I.B.M.T.; writing-review and editing, A.S.E. and I.B.M.T.; visualisation, A.S.E. and I.B.M.T.; supervision, A.S.E.; project administration, A.S.E.; funding acquisition, I.B.M.T. All authors have read and agreed to the published version of the manuscript.

Funding: This research received no external funding.

Institutional Review Board Statement: Not applicable.

Informed Consent Statement: Not applicable.

Data Availability Statement: The data presented in this study are available on request from the corresponding author.

Acknowledgments: The authors would like to acknowledge the financial support received from Taif University Researchers Supporting Project Number (TURSP-2020/61), Taif University, Taif, Saudi Arabia.

Conflicts of Interest: The authors declare that no conflict of interest.

\section{Appendix A. Experimental Data}

Table A1. Data of specimens tested by Lindner and Aschinger [1].

\begin{tabular}{ccccccccc}
\hline \multirow{2}{*}{$\begin{array}{c}\text { Specimen } \\
\text { ID }\end{array}$} & $\boldsymbol{h}_{\boldsymbol{w}}$ & $\boldsymbol{a}$ & $\boldsymbol{t}_{\boldsymbol{w}}$ & \multicolumn{2}{c}{ Corrugation Dimensions } & $\boldsymbol{F}_{\boldsymbol{y} \boldsymbol{w}}$ & Web \\
\cline { 1 - 1 } L1A & 994 & 974 & 2 & 140 & 50.03 & 50 & 292 & 512.37 \\
L1B & 994 & 984 & 3 & 140 & 50.03 & 50 & 335 & 383.78 \\
L2A & 1445 & 1503 & 2 & 140 & 50.03 & 50 & 282 & 744.85 \\
L2B & 1445 & 1503 & 3 & 140 & 50.03 & 50 & 317 & 568.90 \\
L3A & 2005 & 2005 & 2 & 140 & 50.03 & 50 & 280 & 997.51 \\
L3B & 2005 & 2005 & 3 & 140 & 50.03 & 50 & 300 & 792.49 \\
B1 & 600 & 798 & 2 & 140 & 50.03 & 50 & 341 & 285.71 \\
B4 & 600 & 798 & 2 & 140 & 50.03 & 50 & 363 & 284.36 \\
B4b & 600 & 798 & 2 & 140 & 50.03 & 50 & 363 & 284.36 \\
B3 & 600 & 798 & 3 & 140 & 50.03 & 50 & 317 & 229.01 \\
B2 & 600 & 702 & 3 & 140 & 50.03 & 50 & 315 & 229.01 \\
M101 & 600 & 600 & 1 & 70 & 15.01 & 15 & 189 & 606.06 \\
M102 & 800 & 800 & 1 & 70 & 15.01 & 15 & 190 & 808.08 \\
M103 & 1000 & 1000 & 1 & 70 & 15.01 & 15 & 213 & 1052.63 \\
M104 & 1200 & 1200 & 1 & 70 & 15.01 & 15 & 189 & 1212.12 \\
L1 & 1000 & 1500 & 2 & 106 & 50.02 & 87 & 410 & 476.19 \\
L1 & 1000 & 1490 & 3 & 106 & 50.02 & 87 & 450 & 333.33 \\
L2 & 1498 & 2157 & 2 & 106 & 50.02 & 87 & 376 & 749.00 \\
L2 & 1498 & 2142 & 3 & 106 & 50.02 & 87 & 402 & 499.33 \\
No. 1 & 850 & 1131 & 2 & 102 & 55.55 & 86 & 355 & 425.00 \\
No. 2 & 850 & 1131 & 2 & 91 & 56.30 & 72 & 349 & 425.00 \\
V1/1 & 298 & 2819 & 2 & 144 & 102.06 & 102 & 298 & 145.37 \\
V1/2 & 298 & 2000 & 2 & 144 & 102.06 & 102 & 283 & 141.90 \\
V1/3 & 298 & 1001 & 2 & 144 & 102.06 & 102 & 298 & 149.00 \\
V2/3 & 600 & 1650 & 3 & 144 & 102.06 & 102 & 279 & 200.00 \\
\hline
\end{tabular}


Table A2. Data of specimens tested by Elgaaly et al. [2].

\begin{tabular}{|c|c|c|c|c|c|c|c|c|}
\hline \multirow{2}{*}{$\begin{array}{l}\text { Specimen } \\
\text { ID }\end{array}$} & \multirow{2}{*}{$h_{w}$} & \multirow{2}{*}{$a$} & \multirow{2}{*}{$t_{w}$} & \multicolumn{3}{|c|}{ Corrugation Dimensions } & \multirow{2}{*}{$F_{y w}$} & \multirow{2}{*}{$\begin{array}{c}\text { Web } \\
\text { Slenderness }\end{array}$} \\
\hline & & & & $b$ & $h_{r}$ & $d$ & & \\
\hline V-PILOTA & 305 & 305 & 0.78 & 38.10 & 25.42 & 25.40 & 621 & 390.03 \\
\hline V-PILOTB & 305 & 305 & 0.79 & 38.10 & 25.42 & 25.40 & 638 & 388.54 \\
\hline V121216A & 305 & 305 & 0.64 & 38.10 & 25.42 & 25.40 & 676 & 478.06 \\
\hline V121216B & 305 & 305 & 0.77 & 38.10 & 25.42 & 25.40 & 665 & 398.69 \\
\hline V181216B & 457 & 305 & 0.61 & 38.10 & 25.42 & 25.40 & 618 & 749.18 \\
\hline V181216C & 457 & 305 & 0.76 & 38.10 & 25.42 & 25.40 & 679 & 602.11 \\
\hline V181816A & 457 & 457 & 0.64 & 38.10 & 25.42 & 25.40 & 591 & 719.69 \\
\hline V181816B & 457 & 457 & 0.74 & 38.10 & 25.42 & 25.40 & 614 & 620.08 \\
\hline V241216A & 610 & 305 & 0.64 & 38.10 & 25.42 & 25.40 & 591 & 960.63 \\
\hline V241216B & 610 & 305 & 0.79 & 38.10 & 25.42 & 25.40 & 588 & 775.10 \\
\hline V121221A & 305 & 305 & 0.63 & 41.90 & 33.45 & 23.40 & 665 & 484.13 \\
\hline V121221B & 305 & 305.00 & 0.79 & 41.90 & 33.45 & 23.40 & 665 & 388.54 \\
\hline V122421A & 305 & 609.60 & 0.68 & 41.90 & 33.45 & 23.40 & 621 & 451.18 \\
\hline V122421B & 305 & 609.60 & 0.78 & 41.90 & 33.45 & 23.40 & 638 & 390.03 \\
\hline V181221A & 457 & 305 & 0.61 & 41.90 & 33.45 & 23.40 & 578 & 749.18 \\
\hline V181221B & 457 & 305 & 0.76 & 41.90 & 33.45 & 23.40 & 606 & 599.74 \\
\hline V181821A & 457 & 457 & 0.64 & 41.90 & 33.45 & 23.40 & 552 & 719.69 \\
\hline V181821B & 457 & 457 & 0.74 & 41.90 & 33.45 & 23.40 & 596 & 620.08 \\
\hline V241221A & 610 & 305 & 0.61 & 41.90 & 33.45 & 23.40 & 610 & 1000.00 \\
\hline V241221B & 610 & 305 & 0.76 & 41.90 & 33.45 & 23.40 & 639 & 800.52 \\
\hline V121232A & 305 & 305 & 0.64 & 49.80 & 50.77 & 26.40 & 665 & 476.56 \\
\hline V121232B & 305 & 305 & 0.78 & 49.80 & 50.77 & 26.40 & 641 & 391.03 \\
\hline V121832A & 305 & 457 & 0.64 & 49.80 & 50.77 & 26.40 & 703 & 476.56 \\
\hline V121832B & 305 & 457 & 0.92 & 49.80 & 50.77 & 26.40 & 562 & 331.88 \\
\hline V122432A & 305 & 609.60 & 0.64 & 49.80 & 50.77 & 26.40 & 714 & 476.56 \\
\hline V122432B & 305 & 609.60 & 0.78 & 49.80 & 50.77 & 26.40 & 634 & 392.54 \\
\hline V181232A & 457 & 305 & 0.60 & 49.80 & 50.77 & 26.40 & 552 & 765.49 \\
\hline V181232B & 457 & 305 & 0.75 & 49.80 & 50.77 & 26.40 & 602 & 610.15 \\
\hline V181832A & 457 & 457 & 0.61 & 49.80 & 50.77 & 26.40 & 689 & 749.18 \\
\hline V181832B & 457 & 457 & 0.75 & 49.80 & 50.77 & 26.40 & 580 & 610.15 \\
\hline V241232A & 610 & 305.00 & 0.62 & 49.80 & 50.77 & 26.40 & 673 & 980.71 \\
\hline V241232B & 610 & 305.00 & 0.76 & 49.80 & 50.77 & 26.40 & 584 & 800.52 \\
\hline V121809A & 305 & 457.00 & 0.71 & 19.80 & 14.19 & 11.90 & 572 & 432.01 \\
\hline V121809C & 305 & 457.00 & 0.63 & 19.80 & 14.19 & 11.90 & 669 & 482.59 \\
\hline V122409A & 305 & 609.60 & 0.71 & 19.80 & 14.19 & 11.90 & 586 & 427.17 \\
\hline V122409C & 305 & 609.60 & 0.66 & 19.80 & 14.19 & 11.90 & 621 & 460.03 \\
\hline V181209A & 457 & 305.00 & 0.56 & 19.80 & 14.19 & 11.90 & 689 & 817.53 \\
\hline V181209C & 457 & 305.00 & 0.61 & 19.80 & 14.19 & 11.90 & 592 & 749.18 \\
\hline V181809A & 457 & 457.00 & 0.61 & 19.80 & 14.19 & 11.90 & 618 & 749.18 \\
\hline V181809C & 457 & 457.00 & 0.62 & 19.80 & 14.19 & 11.90 & 559 & 734.73 \\
\hline V241209A & 610 & 305.00 & 0.62 & 19.80 & 14.19 & 11.90 & 606 & 980.71 \\
\hline V241209C & 610 & 305.00 & 0.64 & 19.80 & 14.19 & 11.90 & 621 & 960.63 \\
\hline
\end{tabular}

Table A3. Data of specimens tested by Johnson and Cafolla [26].

\begin{tabular}{ccccccccc}
\hline \multirow{2}{*}{$\begin{array}{c}\text { Specimen } \\
\text { ID }\end{array}$} & $\boldsymbol{h}_{\boldsymbol{w}}$ & $\boldsymbol{a}$ & $\boldsymbol{t}_{\boldsymbol{w}}$ & \multicolumn{2}{c}{ Corrugation Dimensions } & \multirow{2}{*}{$\boldsymbol{F}_{\boldsymbol{y} w}$} & \multirow{2}{*}{$\begin{array}{c}\text { Web } \\
\text { Slenderness }\end{array}$} \\
\hline CW1 & 440.36 & 730.92 & 3.06 & 180 & 45.01 & 44.99 & 320 & 143.91 \\
CW2 & 437.92 & 730.92 & 3.29 & 180 & 45.01 & 44.99 & 312 & 133.11 \\
CW3 & 437.18 & 940.92 & 3.26 & 250 & 45.01 & 44.99 & 284 & 134.10 \\
\hline
\end{tabular}


Table A4. Data of specimens tested by Peil [27].

\begin{tabular}{ccccccccc}
\hline $\begin{array}{c}\text { Specimen } \\
\text { ID }\end{array}$ & $\boldsymbol{h}_{\boldsymbol{w}}$ & $\boldsymbol{a}$ & $\boldsymbol{t}_{\boldsymbol{w}}$ & \multicolumn{2}{c}{ Corrugation Dimensions } & \multirow{2}{*}{$\boldsymbol{F}_{\boldsymbol{y} \boldsymbol{w}}$} & $\begin{array}{c}\text { Web } \\
\text { Slenderness }\end{array}$ \\
\cline { 7 - 8 } SP1 & 800 & 1750 & 2 & 146 & 104.07 & 104 & 307 & 400 \\
SP2 & 800 & 1750 & 2 & 170 & 80.05 & 80 & 299 & 400 \\
SP3 & 800 & 1750 & 2 & 185 & 65.04 & 65 & 292 & 400 \\
SP4 & 800 & 1800 & 2 & 117 & 83.05 & 83 & 298 & 400 \\
SP5 & 800 & 1800 & 2 & 136 & 64.04 & 64 & 291 & 400 \\
SP6 & 800 & 1800 & 2 & 148 & 52.03 & 52 & 294 & 400 \\
SP2-2-400 1 & 400 & 1000 & 2 & 170 & 80.05 & 80 & 263 & 200 \\
SP2-2-400 2 & 400 & 1000 & 2 & 170 & 80.05 & 80 & 263 & 200 \\
SP2-2-800 1 & 800 & 1000 & 2 & 170 & 80.05 & 80 & 272 & 400 \\
SP2-2-800 2 & 800 & 1000 & 2 & 170 & 80.05 & 80 & 272 & 400 \\
SP2-3-600 1 & 600 & 1000 & 3 & 170 & 80.05 & 80 & 294 & 200 \\
SP2-3-600 2 & 600 & 1000 & 3 & 170 & 80.05 & 80 & 294 & 200 \\
SP2-3-1200 1 & 1200 & 1000 & 3 & 170 & 80.05 & 80 & 294 & 400 \\
SP2-3-1200 2 & 1200 & 1000 & 3 & 170 & 80.05 & 80 & 294 & 400 \\
SP2-4-800 1 & 800 & 1000 & 4 & 170 & 80.05 & 80 & 326 & 200 \\
SP2-4-800 2 & 800 & 1000 & 4 & 170 & 80.05 & 80 & 326 & 200 \\
SP2-4-1600 1 & 1600 & 1000 & 4 & 170 & 80.05 & 80 & 328 & 400 \\
SP2-4-1600 2 & 1600 & 1000 & 4 & 170 & 80.05 & 80 & 328 & 400 \\
SP2-8-800 1 & 800 & 1000 & 8 & 170 & 80.05 & 80 & 270 & 100 \\
SP2-8-800 2 & 800 & 1000 & 8 & 170 & 80.05 & 80 & 270 & 100 \\
\hline
\end{tabular}

Table A5. Data of specimens tested by Driver et al. [5].

\begin{tabular}{ccccccccc}
\hline \multirow{2}{*}{$\begin{array}{c}\text { Specimen } \\
\text { ID }\end{array}$} & $\boldsymbol{h}_{\boldsymbol{w}}$ & $\boldsymbol{a}$ & $\boldsymbol{t}_{\boldsymbol{w}}$ & \multicolumn{2}{c}{ Corrugation Dimensions } & \multirow{2}{*}{$\boldsymbol{F}_{\boldsymbol{y} w}$} & \multirow{2}{*}{$\begin{array}{c}\text { Web } \\
\text { Slenderness }\end{array}$} \\
\cline { 1 - 4 } G7A & 1500 & 4500 & 6 & 300 & 150 & 200 & 465 & 250 \\
G8A & 1500 & 4500 & 6 & 300 & 150 & 200 & 465 & 250 \\
\hline
\end{tabular}

Table A6. Data of specimens tested by Lee et al. [28].

\begin{tabular}{ccccccccc}
\hline \multirow{2}{*}{$\begin{array}{c}\text { Specimen } \\
\text { ID }\end{array}$} & $\boldsymbol{h}_{\boldsymbol{w}}$ & $\boldsymbol{a}$ & $\boldsymbol{t}_{\boldsymbol{w}}$ & \multicolumn{2}{c}{ Corrugation Dimensions } & \multirow{2}{*}{$\boldsymbol{F}_{\boldsymbol{y} w}$} & \multirow{2}{*}{$\begin{array}{c}\text { Web } \\
\text { Slenderness }\end{array}$} \\
\hline L1 & 1500 & 3000 & 4.80 & 450 & 200.00 & 300 & 250 & 312.50 \\
L2 & 1500 & 3400 & 4.80 & 550 & 188.80 & 300 & 250 & 312.50 \\
L3 & 1500 & 3000 & 4.80 & 450 & 49.60 & 300 & 250 & 312.50 \\
L4 & 1500 & 3400 & 4.80 & 550 & 55.60 & 300 & 250 & 312.50 \\
I1 & 2000 & 3600 & 4.80 & 320 & 44.60 & 100 & 250 & 416.67 \\
I2 & 2000 & 3600 & 3.80 & 350 & 28.60 & 100 & 250 & 526.32 \\
G1 & 2000 & 3000 & 4.80 & 200 & 45.40 & 180 & 250 & 416.67 \\
G2 & 2000 & 3000 & 3.80 & 160 & 33.00 & 50 & 250 & 526.32 \\
G3 & 2000 & 3000 & 3.80 & 160 & 26.90 & 100 & 250 & 526.32 \\
\hline
\end{tabular}

Table A7. Data of specimens tested by Moon et al. [7].

\begin{tabular}{ccccccccc}
\hline \multirow{2}{*}{$\begin{array}{c}\text { Specimen } \\
\text { ID }\end{array}$} & \multirow{2}{*}{$\boldsymbol{h}_{\boldsymbol{w}}$} & $\boldsymbol{a}$ & $\boldsymbol{t}_{\boldsymbol{w}}$ & \multicolumn{2}{c}{ Corrugation Dimensions } & \multirow{2}{*}{$\boldsymbol{F}_{\boldsymbol{y} w}$} & \multirow{2}{*}{$\begin{array}{c}\text { Web } \\
\text { Slenderness }\end{array}$} \\
\hline PG2 & 2000 & 2600 & 4 & 250 & 60 & 220 & 296 & 500 \\
PG1 & 2000 & 2800 & 4 & 220 & 60 & 180 & 296 & 500 \\
PG3 & 2000 & 2800 & 4 & 220 & 75 & 180 & 296 & 500 \\
\hline
\end{tabular}


Table A8. Data of specimens tested by Moussa et al. [29].

\begin{tabular}{|c|c|c|c|c|c|c|c|c|}
\hline \multirow{2}{*}{ Specimen ID } & \multirow{2}{*}{$h_{w}$} & \multirow{2}{*}{$a$} & \multirow{2}{*}{$t_{w}$} & \multicolumn{3}{|c|}{ Corrugation Dimensions } & \multirow{2}{*}{$F_{y w}$} & \multirow{2}{*}{$\begin{array}{c}\text { Web } \\
\text { Slenderness }\end{array}$} \\
\hline & & & & $b$ & $h_{r}$ & $d$ & & \\
\hline TP20-300-30 & 3050 & 664.90 & 2 & 60 & 20.01 & 34.64 & 290 & 152.50 \\
\hline A20-410-30-N & 410 & 578.10 & 2 & 40 & 20.01 & 34.64 & 290 & 205.00 \\
\hline A20-410-45-N & 410 & 524.80 & 2 & 40 & 28.29 & 28.28 & 290 & 205.00 \\
\hline A20-505-30-N & 505 & 575.70 & 2 & 40 & 20.01 & 34.64 & 290 & 252.50 \\
\hline A20-505-45-N & 505 & 525.20 & 2 & 40 & 28.29 & 28.28 & 290 & 252.50 \\
\hline B20-305-30 & 305 & 427.00 & 2 & 40 & 20.01 & 34.64 & 680 & 152.50 \\
\hline B20-305-45 & 305 & 390.40 & 2 & 40 & 28.29 & 28.28 & 680 & 152.50 \\
\hline В20-505-45 & 505 & 388.85 & 2 & 40 & 28.29 & 28.28 & 680 & 252.50 \\
\hline B20-505-45-N & 505 & 388.85 & 2 & 40 & 28.29 & 28.28 & 290 & 252.50 \\
\hline
\end{tabular}

Table A9. Test data reported by Wang et al. [30], Sause [8] and Hannebauer [31].

\begin{tabular}{ccccccccc}
\hline \multirow{2}{*}{$\begin{array}{c}\text { Specimen } \\
\text { ID }\end{array}$} & $\boldsymbol{h}_{\boldsymbol{w}}$ & $\boldsymbol{a}$ & $\boldsymbol{t}_{\boldsymbol{w}}$ & \multicolumn{2}{c}{ Corrugation Dimensions } & \multirow{2}{*}{$\boldsymbol{F}_{\boldsymbol{y} w}$} & \multirow{2}{*}{$\begin{array}{c}\text { Web } \\
\text { Slenderness }\end{array}$} \\
\hline W1 & 1200 & 2000 & 3 & 110 & 55 & 90 & 400 & 400 \\
SC1 & 1500 & 4500 & 6.27 & 300 & 150 & 200 & 465 & 239.23 \\
V1b & 500 & 1000 & 2.50 & 30 & 40 & 47 & 270 & 200 \\
\hline
\end{tabular}

Table A10. Analysis results of test specimens reported by Lindner and Aschinger [1].

\begin{tabular}{ccccccccc}
\hline Specimen ID & $\lambda_{L}$ & $\lambda_{G}$ & $\lambda_{I, 1}$ & $\rho_{e}$ & $\zeta$ & $V(\mathbf{k N})$ & $V_{T}(\mathbf{k N})$ & $V / V_{T}$ \\
\hline L1A & 0.953 & 0.53 & 1.09 & 0.70 & 1.255 & 281.72 & 280.93 & 1.01 \\
L1B & 0.765 & 0.53 & 0.93 & 0.80 & 1.238 & 495.08 & 501.34 & 0.98 \\
L2A & 0.937 & 0.76 & 1.21 & 0.63 & 1.222 & 347.69 & 337.50 & 1.04 \\
L2B & 0.759 & 0.75 & 1.07 & 0.71 & 1.182 & 571.69 & 563.51 & 1.00 \\
L3A & 0.901 & 1.04 & 1.38 & 0.52 & 1.384 & 465.59 & 451.22 & 1.05 \\
L3B & 0.741 & 1.02 & 1.26 & 0.60 & 1.460 & 776.65 & 773.57 & 0.99 \\
B1 & 0.952 & 0.34 & 1.01 & 0.75 & 1.056 & 202.53 & 208.04 & 0.94 \\
B4 & 0.977 & 0.35 & 1.04 & 0.73 & 1.062 & 203.28 & 183.46 & 1.12 \\
B4b & 0.977 & 0.35 & 1.04 & 0.73 & 1.062 & 203.28 & 217.66 & 0.95 \\
B3 & 0.735 & 0.31 & 0.80 & 0.88 & 1.008 & 255.36 & 246.01 & 1.04 \\
B2 & 0.733 & 0.31 & 0.80 & 0.88 & 1.061 & 263.45 & 273.42 & 0.98 \\
M101 & 0.751 & 0.74 & 1.05 & 0.72 & 1.153 & 53.46 & 52.96 & 1.02 \\
M102 & 0.753 & 0.99 & 1.24 & 0.60 & 1.507 & 79.10 & 79.19 & 1.00 \\
M103 & 0.831 & 1.32 & 1.56 & 0.41 & 1.751 & 83.79 & 83.95 & 1.00 \\
M104 & 0.751 & 1.48 & 1.66 & 0.36 & 2.168 & 102.33 & 103.98 & 0.98 \\
L1 & 0.790 & 0.66 & 1.03 & 0.74 & 1.045 & 383.35 & 380.08 & 1.01 \\
L1 & 0.579 & 0.63 & 0.86 & 0.84 & 0.945 & 617.09 & 610.72 & 1.01 \\
L2 & 0.794 & 0.96 & 1.25 & 0.60 & 1.506 & 592.39 & 600.20 & 0.98 \\
L2 & 0.548 & 0.90 & 1.05 & 0.72 & 1.202 & 899.87 & 905.32 & 1.00 \\
No. 1 & 0.743 & 0.48 & 0.88 & 0.83 & 0.948 & 272.59 & 275.01 & 0.99 \\
No. 2 & 0.657 & 0.47 & 0.81 & 0.87 & 0.918 & 272.46 & 264.27 & 1.04 \\
V1/1 & 0.939 & 0.10 & 0.94 & 0.79 & 0.820 & 67.96 & 67.98 & 1.00 \\
V1/2 & 0.894 & 0.09 & 0.90 & 0.82 & 0.837 & 69.87 & 69.84 & 1.00 \\
V1/3 & 0.963 & 0.10 & 0.97 & 0.77 & 0.992 & 79.08 & 80.93 & 0.97 \\
V2/3 & 0.621 & 0.17 & 0.64 & 0.97 & 0.844 & 236.78 & 234.89 & 1.01 \\
\hline
\end{tabular}


Table A11. Analysis result of test specimens reported by Elgaaly et al. [2].

\begin{tabular}{|c|c|c|c|c|c|c|c|c|}
\hline Specimen ID & $\lambda_{L}$ & $\lambda_{G}$ & $\lambda_{I, 1}$ & $\rho_{e}$ & $\zeta$ & $V(\mathbf{k N})$ & $V_{T}(\mathrm{kN})$ & $V / V_{T}$ \\
\hline V-PILOTA & 0.939 & 0.52 & 1.07 & 0.71 & 1.284 & 76.65 & 82.73 & 0.94 \\
\hline V-PILOTB & 0.948 & 0.52 & 1.08 & 0.70 & 1.290 & 78.78 & 71.17 & 1.12 \\
\hline V121216A & 1.200 & 0.57 & 1.33 & 0.55 & 1.249 & 50.51 & 50.05 & 1.05 \\
\hline V121216B & 0.993 & 0.54 & 1.13 & 0.67 & 1.300 & 80.36 & 87.63 & 0.90 \\
\hline V181216B & 1.200 & 0.82 & 1.46 & 0.47 & 1.870 & 89.05 & 93.41 & 0.94 \\
\hline V181216C & 1.011 & 0.82 & 1.30 & 0.57 & 1.537 & 117.97 & 119.47 & 1.00 \\
\hline V181816A & 1.128 & 0.80 & 1.38 & 0.52 & 1.492 & 75.66 & 74.73 & 1.03 \\
\hline V181816B & 0.990 & 0.78 & 1.26 & 0.59 & 1.370 & 96.48 & 96.17 & 1.01 \\
\hline V241216A & 1.128 & 1.06 & 1.55 & 0.42 & 1.423 & 77.15 & 75.57 & 1.04 \\
\hline V241216B & 0.908 & 1.01 & 1.35 & 0.54 & 1.494 & 133.19 & 133.35 & 0.98 \\
\hline V121221A & 1.326 & 0.45 & 1.40 & 0.51 & 1.238 & 47.01 & 46.26 & 1.01 \\
\hline V121221B & 1.064 & 0.42 & 1.15 & 0.67 & 1.188 & 75.75 & 72.50 & 1.00 \\
\hline V122421A & 1.194 & 0.42 & 1.27 & 0.59 & 1.034 & 44.47 & 43.28 & 1.04 \\
\hline V122421B & 1.046 & 0.41 & 1.13 & 0.68 & 1.017 & 61.61 & 61.20 & 0.99 \\
\hline V181221A & 1.277 & 0.63 & 1.42 & 0.49 & 1.380 & 64.04 & 61.83 & 1.02 \\
\hline V181221B & 1.046 & 0.61 & 1.21 & 0.62 & 1.301 & 99.89 & 97.86 & 1.01 \\
\hline V181821A & 1.198 & 0.61 & 1.34 & 0.54 & 1.208 & 58.44 & 56.49 & 1.07 \\
\hline V181821B & 1.073 & 0.61 & 1.23 & 0.61 & 1.269 & 92.84 & 93.41 & 0.96 \\
\hline V241221A & 1.312 & 0.86 & 1.57 & 0.41 & 1.481 & 78.46 & 77.26 & 1.02 \\
\hline V241221B & 1.075 & 0.84 & 1.36 & 0.53 & 1.403 & 130.66 & 126.72 & 1.01 \\
\hline V121232A & 1.782 & 0.30 & 1.81 & 0.31 & 1.702 & 39.58 & 41.14 & 0.95 \\
\hline V121232B & 1.436 & 0.28 & 1.46 & 0.47 & 1.460 & 59.92 & 61.16 & 0.98 \\
\hline V121832A & 1.833 & 0.31 & 1.86 & 0.29 & 1.493 & 34.40 & 34.47 & 0.99 \\
\hline V121832B & 1.141 & 0.25 & 1.17 & 0.65 & 0.994 & 54.68 & 53.38 & 1.10 \\
\hline V122432A & 1.847 & 0.31 & 1.87 & 0.28 & 1.360 & 31.35 & 31.14 & 1.00 \\
\hline V122432B & 1.434 & 0.28 & 1.46 & 0.47 & 1.175 & 49.14 & 48.93 & 0.98 \\
\hline V181232A & 1.741 & 0.42 & 1.79 & 0.31 & 1.848 & 49.76 & 51.60 & 0.97 \\
\hline V181232B & 1.449 & 0.41 & 1.51 & 0.44 & 1.536 & 79.59 & 80.06 & 1.00 \\
\hline V181832A & 1.904 & 0.47 & 1.96 & 0.26 & 1.810 & 52.07 & 52.93 & 0.99 \\
\hline V181832B & 0.939 & 0.52 & 1.07 & 0.71 & 1.284 & 76.65 & 82.73 & 0.94 \\
\hline V241232A & 1.422 & 0.41 & 1.48 & 0.46 & 1.505 & 78.12 & 78.64 & 1.00 \\
\hline V241232B & 1.845 & 0.61 & 1.94 & 0.26 & 1.765 & 69.16 & 69.08 & 1.00 \\
\hline V121809A & 1.403 & 0.54 & 1.50 & 0.44 & 1.485 & 103.31 & 101.46 & 1.01 \\
\hline V121809C & 0.519 & 0.78 & 0.94 & 0.79 & 1.070 & 62.39 & 63.16 & 0.95 \\
\hline V122409A & 0.626 & 0.87 & 1.07 & 0.71 & 1.101 & 56.55 & 55.16 & 1.05 \\
\hline V122409C & 0.519 & 0.79 & 0.95 & 0.79 & 1.026 & 59.74 & 57.82 & 1.03 \\
\hline V181209A & 0.575 & 0.83 & 1.01 & 0.75 & 1.061 & 57.65 & 57.82 & 1.00 \\
\hline V181209C & 0.719 & 1.37 & 1.54 & 0.42 & 1.880 & 79.95 & 80.95 & 0.99 \\
\hline V181809A & 0.611 & 1.24 & 1.38 & 0.52 & 1.766 & 87.08 & 88.78 & 0.99 \\
\hline V181809C & 0.624 & 1.27 & 1.41 & 0.50 & 1.626 & 83.94 & 82.29 & 0.99 \\
\hline V241209A & 0.582 & 1.20 & 1.33 & 0.55 & 1.584 & 77.56 & 77.62 & 1.03 \\
\hline V241209C & 0.606 & 1.67 & 1.77 & 0.32 & 1.737 & 71.90 & 70.77 & 1.04 \\
\hline
\end{tabular}

Table A12. Analysis results of test specimens reported by Johnson and Cafolla [26].

\begin{tabular}{ccccccccc}
\hline Specimen ID & $\lambda_{L}$ & $\lambda_{G}$ & $\lambda_{I, \mathbf{1}}$ & $\rho_{e}$ & $\zeta$ & $V(\mathbf{k N})$ & $V_{T}(\mathbf{k N})$ & $V / V_{T}$ \\
\hline CW1 & 0.813 & 0.34 & 0.88 & 0.83 & 0.660 & 133.74 & 126.59 & 1.07 \\
CW2 & 0.747 & 0.33 & 0.82 & 0.87 & 0.669 & 152.26 & 150.56 & 1.00 \\
CW3 & 0.999 & 0.35 & 1.06 & 0.72 & 0.667 & 110.05 & 100.22 & 1.12 \\
\hline
\end{tabular}


Table A13. Analysis results of test specimens reported by Peil [27].

\begin{tabular}{ccccccccc}
\hline Specimen ID & $\lambda_{L}$ & $\lambda_{G}$ & $\lambda_{I, 1}$ & $\rho_{e}$ & $\zeta$ & $V(\mathbf{k N})$ & $V_{T}(\mathbf{k N})$ & $V / V_{T}$ \\
\hline SP1 & 0.996 & 0.26 & 1.03 & 0.74 & 1.077 & 224.99 & 225.00 & 1.00 \\
SP2 & 1.136 & 0.35 & 1.19 & 0.64 & 1.202 & 213.74 & 215.30 & 0.98 \\
SP3 & 1.222 & 0.44 & 1.30 & 0.57 & 1.324 & 205.69 & 209.50 & 0.97 \\
SP4 & 0.783 & 0.30 & 0.84 & 0.85 & 0.999 & 232.31 & 230.80 & 1.02 \\
SP5 & 0.897 & 0.41 & 0.99 & 0.76 & 1.095 & 222.07 & 220.50 & 1.02 \\
SP6 & 0.981 & 0.53 & 1.11 & 0.68 & 1.177 & 218.68 & 220.00 & 0.99 \\
SP2-2-400 1 & 1.066 & 0.16 & 1.08 & 0.71 & 0.981 & 84.29 & 80.25 & 1.05 \\
SP2-2-400 2 & 1.066 & 0.16 & 1.08 & 0.71 & 0.981 & 84.29 & 88.13 & 0.95 \\
SP2-2-800 1 & 1.084 & 0.33 & 1.13 & 0.67 & 1.060 & 178.87 & 178.88 & 1.00 \\
SP2-2-800 2 & 1.084 & 0.33 & 1.13 & 0.67 & 1.060 & 178.87 & 177.75 & 1.01 \\
SP2-3-600 1 & 0.751 & 0.24 & 0.79 & 0.89 & 1.121 & 302.98 & 301.50 & 1.00 \\
SP2-3-600 2 & 0.751 & 0.24 & 0.79 & 0.89 & 1.121 & 302.98 & 308.63 & 0.98 \\
SP2-3-1200 1 & 0.751 & 0.47 & 0.89 & 0.82 & 1.221 & 614.51 & 611.25 & 1.01 \\
SP2-3-1200 2 & 0.751 & 0.47 & 0.89 & 0.82 & 1.221 & 614.51 & 625.13 & 0.98 \\
SP2-4-800 1 & 0.593 & 0.31 & 0.67 & 0.96 & 1.056 & 603.28 & 601.50 & 1.01 \\
SP2-4-800 2 & 0.593 & 0.31 & 0.67 & 0.96 & 1.056 & 603.28 & 603.38 & 1.01 \\
SP2-4-1600 1 & 0.595 & 0.62 & 0.86 & 0.84 & 1.197 & 1218.89 & 1215.38 & 1.00 \\
SP2-4-1600 2 & 0.595 & 0.62 & 0.86 & 0.84 & 1.197 & 1218.89 & 1227.00 & 0.99 \\
SP2-8-800 1 & 0.270 & 0.24 & 0.36 & 1.00 & 1.330 & 1332.58 & 1308.38 & 1.01 \\
SP2-8-800 2 & 0.270 & 0.24 & 0.36 & 1.00 & 1.330 & 1332.58 & 1374.75 & 0.97 \\
\hline
\end{tabular}

Table A14. Analysis results of test specimens reported by Driver et al. [5].

\begin{tabular}{ccccccccc}
\hline Specimen ID & $\lambda_{L}$ & $\lambda_{G}$ & $\lambda_{I, 1}$ & $\rho_{e}$ & $\zeta$ & $V(\mathbf{k N})$ & $V_{T}(\mathbf{k N})$ & $V / V_{T}$ \\
\hline G7A & 0.834 & 0.37 & 0.91 & 0.81 & 1.084 & 2190.70 & 2299.82 & 0.92 \\
G8A & 0.834 & 0.37 & 0.91 & 0.81 & 1.084 & 2190.70 & 2155.05 & 0.98 \\
\hline
\end{tabular}

Table A15. Analysis results of test specimens reported by Lee et al. [28].

\begin{tabular}{ccccccccc}
\hline Specimen ID & $\lambda_{L}$ & $\lambda_{G}$ & $\lambda_{I, \mathbf{1}}$ & $\rho_{\boldsymbol{e}}$ & $\zeta$ & $\boldsymbol{V}(\mathbf{k N})$ & $V_{T}(\mathbf{k N})$ & $V / V_{T}$ \\
\hline L1 & 1.146 & 0.22 & 1.17 & 0.65 & 1.097 & 743.50 & 745.62 & 1.00 \\
L2 & 1.401 & 0.23 & 1.42 & 0.50 & 1.209 & 624.38 & 625.56 & 1.00 \\
L3 & 1.146 & 0.63 & 1.31 & 0.57 & 0.921 & 540.06 & 532.02 & 1.02 \\
L4 & 1.401 & 0.56 & 1.51 & 0.44 & 1.052 & 480.55 & 474.73 & 1.01 \\
I1 & 0.815 & 0.86 & 1.18 & 0.64 & 1.463 & 1302.50 & 1313.50 & 0.99 \\
I2 & 1.126 & 1.26 & 1.69 & 0.35 & 1.475 & 565.15 & 565.66 & 1.00 \\
G1 & 0.509 & 0.91 & 1.04 & 0.73 & 1.077 & 1087.70 & 1095.96 & 0.99 \\
G2 & 0.515 & 1.14 & 1.25 & 0.60 & 1.392 & 916.69 & 912.94 & 1.01 \\
G3 & 0.515 & 1.39 & 1.48 & 0.46 & 1.759 & 888.05 & 929.62 & 0.94 \\
\hline
\end{tabular}

Table A16. Analysis results of test specimens reported by Moon et al. [7].

\begin{tabular}{ccccccccc}
\hline Specimen ID & $\lambda_{L}$ & $\lambda_{G}$ & $\lambda_{I, \mathbf{1}}$ & $\rho_{\boldsymbol{e}}$ & $\zeta$ & $\boldsymbol{V}(\mathbf{k N})$ & $V_{T}(\mathbf{k N})$ & $V / V_{T}$ \\
\hline PG2 & 0.831 & 0.85 & 1.19 & 0.64 & 0.998 & 869.56 & 873.60 & 0.99 \\
PG1 & 0.732 & 0.87 & 1.13 & 0.67 & 0.946 & 864.75 & 843.20 & 1.03 \\
PG3 & 0.732 & 0.73 & 1.03 & 0.74 & 1.053 & 1052.21 & 1052.80 & 1.01 \\
\hline
\end{tabular}


Table A17. Analysis results of test specimens reported by Moussa [29].

\begin{tabular}{ccccccccc}
\hline Specimen ID & $\lambda_{L}$ & $\lambda_{G}$ & $\lambda_{I, \mathbf{1}}$ & $\rho_{e}$ & $\zeta$ & $V(\mathbf{k N})$ & $V_{T}(\mathbf{k N})$ & $V / V_{T}$ \\
\hline TP20-300-30 & 0.395 & 0.38 & 0.55 & 1.00 & 0.833 & 84.89 & 84.72 & 1.00 \\
A20-410-30-N & 0.263 & 0.45 & 0.52 & 1.00 & 0.899 & 122.74 & 125.09 & 0.99 \\
A20-410-45-N & 0.263 & 0.34 & 0.43 & 1.00 & 0.857 & 118.28 & 116.46 & 1.01 \\
A20-505-30-N & 0.263 & 0.56 & 0.62 & 0.99 & 0.915 & 153.69 & 154.23 & 0.99 \\
A20-505-45-N & 0.263 & 0.42 & 0.50 & 1.00 & 0.895 & 152.72 & 152.49 & 0.99 \\
B20-305-30 & 0.403 & 0.51 & 0.65 & 0.97 & 1.006 & 233.51 & 233.20 & 1.00 \\
B20-305-45 & 0.403 & 0.39 & 0.56 & 1.00 & 1.044 & 248.99 & 251.72 & 0.99 \\
B20-505-45 & 0.403 & 0.64 & 0.76 & 0.90 & 0.976 & 335.82 & 329.34 & 1.06 \\
B20-505-45-N & 0.263 & 0.42 & 0.50 & 1.00 & 0.852 & 150.59 & 150.43 & 0.96 \\
\hline
\end{tabular}

Table A18. Analysis results of test specimens reported by Wang et al. [30], Sause [8] and Hannebauer [31].

\begin{tabular}{ccccccccc}
\hline Scheme 1. & $\lambda_{L}$ & $\lambda_{G}$ & $\lambda_{I, \mathbf{1}}$ & $\rho_{\boldsymbol{e}}$ & $\zeta$ & $\boldsymbol{V} \mathbf{( k N )}$ & $V_{T}(\mathbf{k N})$ & $V / V_{T}$ \\
\hline W1 & 0.567 & 0.66 & 0.87 & 0.83 & 0.858 & 587.62 & 567.00 & 1.05 \\
SC1 & 0.798 & 0.36 & 0.88 & 0.83 & 1.088 & 2127.47 & 2007.53 & 1.14 \\
V1b & 0.314 & 0.24 & 0.39 & 1.00 & 1.028 & 200.94 & 206.50 & 0.97 \\
\hline
\end{tabular}

\section{References}

1. Lindner, J.; Aschinger, R. Grenzschubtragfähigkeit von I-trägern mit trapezför- mig profilierten Stegen; Stahlbau: Aurich, Germany, 1988; Volume 57, pp. 377-380.

2. Elgaaly, M.; Hamilton, R.; Seshadri, A. Shear strength of beams with corrugated webs. J. Struct. Eng. 1996, 122, 390-398. [CrossRef]

3. Sause, R.; Abbas, H.; Wassef, W.; Driver, R.; Elgaaly, M. Corrugated Web Girder Shape and Strength Criteria: Work area 1. Pennsylvania Innovative High Performance Steel Bridge Demonstration Project, ATLSS Report No. 03-18; Lehigh University ATLSS Center: Bethlehem, PA, USA, 2003.

4. Abbas, H. Analysis and Design of Corrugated Web I-Girders for Bridges Using High Performance Steel. Ph.D. Thesis, Department of Civil and Environmental Engineering, Lehigh University, Bethlehem, PA, USA, 2003.

5. Driver, G.; Abbas, H.; Sause, R. Shear behavior of corrugated web bridge girders. J. Struct. Eng. 2006, 132, 195-203. [CrossRef]

6. Yi, J.; Gil, H.; Youm, K.; Lee, H. Interactive shear buckling behavior of trapezoidally corrugated steel webs. Eng. Struct. 2008, 30, 1659-1666. [CrossRef]

7. Moon, J.; Yi, J.; Choi, H.; Lee, H.-E. Shear strength and design of trapezoidally corrugated steel webs. J. Constr. Steel Res. 2008, 65, 1198-1205. [CrossRef]

8. Sause, R.; Braxtan, T. Shear strength of trapezoidal corrugated steel webs. J. Constr. Steel Res. 2011, 67, 223-236. [CrossRef]

9. Bergfelt, A.; Leiva, L. Shear Buckling of Trapezoidally Corrugated Girders Webs, Report Part 2, Pibl.SS4:2; Sweden Chalmers University of Technology: Gothenburg, Sweden, 1984.

10. El-Metwally, A. Prestressed Composite Girders with Corrugated Steel Webs. Master's Thesis, Department of Civil Engineering, University of Calgary, Calgary, AB, Canada, 1998.

11. Abbas, H.; Sause, R.; Driver, R. Shear strength and stability of high performance steel corrugated web girders. Proc. Struct. Stab. Res. Counc. 2002, 361-387.

12. Hiroshi, S.; Hiroyuki, I.; Yohiaki, I.; Koichi, K. Flexural shear behavior of composite bridge girder with corrugated steel webs around middle support. Doboku Gakkai Ronbunshu 2003, 724, 49-67.

13. Ahmed, S. Plate girders with corrugated steel webs. AISC Eng. J. First Quart 2005, 42, 1-13.

14. Elamary, A.; Alharthi, Y.; Abdalla, O.; Alqurashi, M.; Sharaky, I. Failure mechanism of hybrid steel beams with trapezoidal corrugated-web non-welded inclined folds. Materials 2021, 14, 1424. [CrossRef] [PubMed]

15. Kumar, M.; Pradeep, D.; Patel, R.; Pandian, M.; Karthikeyan, K. A study on flexural capacity of steel beams with corrugated web. Int. J. Civ. Eng. Technol. 2018, 9, 679-689.

16. Krejsa, M.; Janas, P.; Čajka, R. Using DOProC method in structural reliability assessment. In Applied Mechanics and Materials; Trans Tech Publications Ltd.: Stafa-Zurich, Switzerland, 2013; pp. 300-301. [CrossRef]

17. Čajka, R.; Krejsa, M. Measured data processing in civil structure using the DOProC method. In Advanced Materials Research; Trans Tech Publications Ltd.: Stafa-Zurich, Switzerland, 2013; Volume 859, pp. 114-121. [CrossRef]

18. Čajka, R.; Krejsa, M. Validating a computational model of a rooflight steel structure by means of a load test. In Applied Mechanics and Materials; Trans Tech Publications Ltd.: Stafa-Zurich, Switzerland, 2014; pp. 592-598. [CrossRef]

19. Flodr, J.; Krejsa, M.; Mikolášek, D.; Sucharda, O.; Žídek, I. Mathematical modelling of thin-walled cold-rolled cross-section. In Applied Mechanics and Materials; Trans Tech Publications Ltd.: Stafa-Zurich, Switzerland, 2014; pp. 171-174. [CrossRef] 
20. Zhu, L.; Guo, L.; Zhou, P. Numerical and experimental studies of corrugated-web-connected buckling-restrained braces. Eng. Struct. 2017, 134, 107-124. [CrossRef]

21. Barakat, S.; Mansouri, A.; Altoubat, S. Shear strength of steel beams with trapezoidal corrugated webs using regression analysis. Steel Compos. Struct. 2015, 18, 757-773. [CrossRef]

22. Timoshenko, S.; Gere, J. Theory of Elastic Stability, 2nd ed.; McGraw-Hill: New York, NY, USA, 1961.

23. Sause, R.; Clarke, T. Bearing Stiffeners and Field Splices For Corrugated Web Girders, Work Area 4, Pennsylvania Innovative High Performance Steel Bridge Demonstration Project ATLSS Report No. 03-21; Lehigh University: Bethlehem, PA, USA, 2003.

24. Easley, J. Buckling formulas for corrugated metal shear diaphragms. J. Struct. Div. 1975, 101, 1403-1413. [CrossRef]

25. Abbas, H.H.; Sause, R.; Driver, R.G. Behavior of corrugated web I-girders under in-plane loads. J. Eng. Mech. ASCE 2006, 132, 806-814. [CrossRef]

26. Johnson, R.; Cafolla, J. Local flange buckling in plate girders with corrugated steel webs. Proc. Inst. Civ. Eng. Struct. Build. 1997, 122, 148-156. [CrossRef]

27. Peil, U. Statische versuche an trapezstegträgern untersuchung der querkraftbeanspruchbarkeit; Institut für Stahlbau, Technischen University of Braunschweig: Braunschweig, Germany, 1998.

28. Gil, H.; Lee, S.; Lee, J.; Lee, H. Shear buckling strength of trapezoidally corrugated steel webs for bridges. J. Transp. Res. Board 2005, 473-480. [CrossRef]

29. Moussa, L.; Barakat, S.; Al-Saadon, Z. Shear behavior of corrugated web panels and sensitivity analysis. J. Constr. Steel Res. 2018, 151, 94-107.

30. Wang, S.; He, J.; Liu, Y. Shear behavior of steel I-girder with stiffened corrugated web, Part I: Experimental study. Thin Walled Struct. 2019, 1, 248-262. [CrossRef]

31. Hannebauer, D. Zur Querschnitts-und Stabtragfähigkeit von Trägern mit profilierten Stegen; Brandenburgischen Technischen Universität: Cottbus, Germany, 2008.

32. Leblouba, M.; Barakat, S.; Altoubat, S.; Junaid, T.; Maalej, M. Normalized shear strength of trapezoidal corrugated steel webs. J. Constr. Steel Res. 2017, 1, 75-90. [CrossRef]

33. Nie, J.; Zhu, I.; Tao, M.; Tang, L. Shear strength of trapezoidal corrugated steel webs. J. Constr. Steel Res. 2013, 85, 105-115. [CrossRef]

34. Available online: https://ch.mathworks.com/help/stats/regression-learner-app.html (accessed on 5 June 2020).

35. Putatunda, S.; Rama, K. A Modified Bayesian Optimization based Hyper-Parameter Tuning Approach for Extreme Gradient Boosting. In Proceedings of the Fifteenth International Conference on Information Processing (ICINPRO), Bengaluru, India, 20-22 December 2019.

36. William, W.; Burank, B.; Efstratios, P. Hyperparameter optimization of machine learning models through parametric programming. Comput. Chem. Eng. 2020, 139, 1-12.

37. Jia, W.; Xiu, C.; Hao, Z.; Li-Diong, X.; Si-Hao, D. Hyperparameter optimization for machine learning models based on bayesian optimization. J. Electron. Sci. Technol. 2019, 17,36-40. 